\title{
Culture and Household Saving
}

\author{
Benjamin Guin*
}

Draft (31 January 2015)

\begin{abstract}
In this paper, I examine the role of culture for households' saving decisions. Exploiting historical language borders within Switzerland, I isolate the effect of culture from economic, institutional, demographic and geographic factors for a homogeneous and representative sample of households. The analysis is based on the Swiss Household Panel that I complement with geographic and socio-economic data. I show that households located in the Romanic-speaking part (Italian, French) are more than 10 percentage points less likely to save than German-speaking households. I show that these differences are consistent with different distributions of time preferences and norms of taking informal consumer credit in financial distress across language regions.
\end{abstract}

${ }^{*}$ Swiss Institute of Banking and Finance, University of St.Gallen (HSG), Switzerland. E-mail: benjamin.guin@unisg.ch. I would like to thank my supervisor Martin Brown for support. Besides, I am grateful to Steffen Andersen, Christoph Basten, Kristian Blickle, Benjamin Enke, Beatrix Eugster, Raymond Fisman, Dimitris Georgarakos, Michael Haliassos, Christian Hattendorff, Raj Iyer, Michael Lechner, Marco Di Maggio, Stephan Meier, Enrichetta Ravina, Stefan Trautmann and seminar participants of the Western Economic Asscociation Conference in Wellington and University of St.Gallen for helpful comments. This paper uses data from the Swiss Household Panel and I thank Beatrix Eugster and Oliver Lipps for further data enrichments. A first draft of this paper was written while I was visiting Columbia Business School; I thank Columbia Business School and Stephan Meier for their hospitality and the Swiss National Science Foundation for financial support. 


\section{Introduction}

There are tremendous differences in household saving and accumulated wealth across countries. Understanding these differences is important as only small changes in aggregate savings rates can affect a country's growth path while low wealth buffers can imperil an economy's financial stability in case of adverse income or expenditure shocks. Typically, economists attempt to explain these differences by economic, institutional, demographic and geographic conditions which vary across countries. These attempts have only been partly successful in explaining the observed differences. This paper analyzes the extent to which exposure to cultural groups can affect households' intertemporal financial decisions - in particular their decision to save. Moreover, it elicits potential channels of how culture affects these decisions.

But what is culture and why should it affect households intertemporal decisions? Only recently, economists have transformed the notion of culture from a vague concept to a clear definition that allows the development of testable empirical predictions. In line with Guiso et al. (2006) and Fernández (2011), I define cultural differences as

systematic variation in norms and preferences shared within social groups.

In this paper, I focus on social groups that share a similar language. I argue that speaking a similar language is a necessary condition for any form of social interaction: it enables the transmission of beliefs and preferences from parents to their children (vertical transmission) or from their peers (horizontal transmission). In line with the existing literature, I test several specific dimensions of norms and preferences. I argue that different distributions of time preferences and norms of taking formal or informal consumer credit in financial distress can affect a households' decision to save: impatient households are more likely to consume today than to save (Sutter et al., 2013). Besides, the norm of mutual help in informal networks of family and friends in case of adverse income or expenditure shocks might lead to lower precautionary saving (Ortigueira and Siassi (2013), Bloch et al. (2008)).

Switzerland is a suitable laboratory to analyze the role of exposure to different language groups on households' intertemporal decisions. In Switzerland, there are two major

language groups: the Romanic languages (French, Italian and Romansh) and German. 
The speakers of these languages are located in separate regions for historically reasons. These regions are geographically close and share a common language border. At this border, the share of Romanic-speaking individuals falls from $80 \%$ to about $20 \%$ within 5 kilometers (vice versa the share of German speaking individuals). A large part of this language border runs through the Swiss cantons.

As policies are set either on the national or on the cantonal level, there is no associated change in policies and institutions at the parts of this border that run through cantons. Besides, there is no change in geographic conditions as the main geographical border, the Alps, runs in East-West direction while the language border mainly runs in North-South direction. In addition, it is reasonable to assume that many relevant economic conditions do not change at the parts of this border that run through cantons (e.g., business cycles, inflation, interest rates and supply of financial products).

Hence, by comparing the financial decisions of similar households on the German-speaking side of the language border to the ones on the Romanic-speaking side, I am able to isolate the effect of the exposure to these language groups on individual decisions from institutional, economic and geographic differences. Being able to do this is important as institutional conditions can affect households' propensity to save through differences in tax incentives (Duflo et al., 2006), pension systems (Börsch-Supan et al., 2008) and unemployment insurance (Engen and Gruber, 2001). Economic conditions might lead to different saving behavior in case of differences in interest rates, inflation (Carroll and Summers, 1987), business cycles (Carroll et al., 2000) or unemployment expectations (Basten et al. 2012). Last, geographic proximity to financial institutions might be relevant for the access to and usage of financial products by households (Degryse and Ongena (2005), Agarwal and Hauswald (2010), Brown et al. (2014)).

To isolate the effect of language group exposure on households' financial decisions, I employ survey data from the Swiss Household Panel (waves 1999 until 2012). It includes characteristics of the person responsible for the management of household finances ("household head") (e.g., age, gender, education, etc.), her preferred language spoken (French, Italian or German) and her religious views. In addition, it contains a wide range of socioeconomic household characteristics such as income, the employment status and the exact location of each household on the municipality level. Besides, it includes variables that have been shown to be good proxies for impatience (e.g., past tobacco consumption) (e.g., Chabris et al. (2008), Khwaja et al. (2006)). 
I complement this data set with data on local unemployment rates on the district leve 1 and bank branches on the ZIP code level.

The empirical strategy is a spatial regression discontinuity design: I test for discontinuities in household savings at the language border. The key identifying assumption of this local border contrast is that only the dominant language of each municipality but no other pre-determined variable $\left.\right|^{2}$ changes household saving at the language border. I argue that this is reasonable to assume - especially for those parts of the language border that run through cantons.

I estimate the effect of households' exposure to language groups on their propensity to save and to spend excessively. Hereby, I mainly rely on a variable that indicates whether a household saves at least $C H F 100$ per month ${ }^{3}$ Alternatively, I employ variables that indicate whether the household has a retirement savings account and whether a household's expenditures are higher than its income. To investigate the potential channels relevant for the cultural differences, I complement the main analysis with two further empirical exercises. First, I test whether different initial distributions of time preferences are consistent with the observed differences in saving. Second, I test whether households in the Romanic-speaking part are more likely to take formal or informal consumer credit in case of financial distress.

I document that households in the Romanic-speaking part are more than 12 percentage points less likely to save and 6 percentage points more likely to spend excessively. These results are robust to more formal testing when implementing the local border contrast. I find evidence that there are differences in norms of taking credit in financial distress and impatience that are consistent with the initial differences in household saving across language regions.

This paper contributes to several strands of the literature: while the role of short-term social interactions among peer:4 has been shown to affect households' decisions to consume (Kuhn et al. (2011), Angelucci and De Giorgi (2009), Luttmer (2005)), take debt (Georgarakos et al., 2014), save for retirement (Duflo and Saez, 2002) and to participate in the stock market (Kaustia and Knüpfer (2012), Brown et al. (2008), Hong et al. (2004),

\footnotetext{
${ }^{1}$ There are 148 districts in Switzerland (as of January 2013).

${ }^{2}$ all variables that are not affected by the dominant language per municipalities themselves.

${ }^{3}$ CHF 100 are about USD 96 (as of October 2014).

${ }^{4}$ which I interpret as the horizontal dimension of culture.
} 
Christelis et al. (2011)), evidence on the role of the long-term vertical dimension of culture for households' financial decisions is still scarce.

Existing research has analyzed the role of culture for household debt and portfolios using cross-country comparisons (e.g., Christelis et al. (2013), Bover et al. (2014), Breuer and Salzmann (2012)) and exploiting financial decisions of immigrants to a country (Carroll et al. (1994), Haliassos et al. (2014)). While the first strand of the literature faces the problem of convincingly disentangle country-specific institutional and economic factors from cultural factors, the second strand faces multiple sample selection issues that arise when comparing different immigrant groups with each other and with the non-immigrant population (Bauer and Sinning (2011), Sinning (2011), Piracha and Zhu (2012)). Besides, in both strands of the literature it remains unclear which of the norms and preferences that are common within cultural groups are relevant for the observed differences in the financial decisions. This paper overcomes these methodological drawbacks by comparing the financial decisions of a representative and homogeneous sample of households within a country. Hereby, I am able to isolate the effect of culture on financial decisions from differences in institutional, economic and geographic conditions and from differences in household characteristics.

By eliciting the channels at work, this paper contributes to the existing literature on how culture shapes differences in norms and preferences. A recently developed linguisticsavings hypothesis argues that the future orientation of language can shape individual time preferences (Chen (2013)). These can, in turn, predict intertemporal financial decisions in controlled laboratory experiments (Sutter et al. (2014)) and across countries (Chen, 2013). The present paper contributes to this literature by providing evidence that language group membership can be indeed relevant for individuals' financial decisions, in particular their decision to save. I find evidence that these decisions are consistent with different initial distributions of time preferences across language groups.

An alternative strand of the literature argues that social norms imply non-pecuniary costs of defaulting on loans (e.g. Guiso et al. (2013), Fay et al. (2002) and Gross and Souleles (2002)). This paper contributes to this strand of literature by showing that there are substantial differences in how households resolve financial distress across cultural groups. These differences are likely to be consistent with non-pecuniary costs - such as social stigma of taking consumer credit in financial distress. 
The remainder of the paper is organized as follows. Section 2 discusses the theoretical framework. Section 3 describes the institutional background to the paper. Section 4 presents the data and methodology. Section 5 shows the empirical results of the role of culture. Section 6 examines the competing channels of culture, and section 7 concludes. 


\section{Theoretical Framework}

In this paper, I argue that exposure to different cultural groups can affect households' saving decisions. Moreover, I argue that time preferences and norms of taking consumer credit in case of financial distress could explain the differences in household saving. In this section, I discuss how different distributions of these norms and preferences can affect precautionary saving in a stylized three-period partial equilibrium model. In this model, a household is faced with the possibility of an uncertain adverse income shock. It can either insure itself $e x$-ante (before income shocks materialize) by conducting precautionary savings or ex-post (after income shocks materialize) by obtaining credit. Getting credit expost is associated with non-pecuniary costs of repayment. These costs can be interpreted as social norms, i.e. social stigma of taking credit. I show that higher non-pecuniary costs lead to a lower propensity to take credit ex-post; which itself leads to a higher propensity to save ex-ante. Besides, higher discount factors lead to higher precautionary savings ex-ante.

\section{$2.1 \quad$ A stylized model}

In this theoretical framework, I assume that a household lives for three periods.

- In period 1 , the household earns exogenous income $Y_{1}=Y$. It can save a portion of this income $S_{1}$ and spends the remaining income on consumption of a non-durable $\operatorname{good} C_{1}$.

- In period 2, the household gets back its initial saving $S_{1}$ (for simplicity I assume that the interest rate is zero) and earns income $\tilde{Y}_{2}$. With probability $1-\pi$ it does not receive an adverse income shock and earns income $Y_{2}=Y$. With probability $\pi$ the household receives an adverse income shock of $\sigma<Y$ and earns income of $Y_{2}=Y-\sigma$. In case of the negative income shock, the household can either borrow $b=\sigma$ to smooth consumption (this implies full ex-post insurance) or not borrow $b=0$ (no ex-post insurance). In period 2 , the household spends its entire income on consumption.

- In period 3, the household receives retirement income of $Y_{3}=Y$. Besides, it has to repay the amount borrowed in period 2 including extra costs of $\rho$. These costs can be interpreted as non-pecuniary costs (i.e. social stigma of taking a consumer loan). 
I assume that the second-period income $\tilde{Y}_{2}$ is unknown in the initial period. The household decides on its initial saving $S_{1}$ in the first period. Subsequently, it decides on borrowing $b$ in the second period if a negative income shock arises. Besides, I assume that the household discounts consumption in the subsequent period with a discount factor of $0<\beta \leq 1$.

To obtain a closed-form solution, I make the following assumptions: First, I assume that utility follows a logarithmic form such that the precautionary saving motive is preserved (e.g. Kimball (1990)). Second, I normalize income to one $(Y=1)$. Third, I assume that negative income shocks occur with probability $\pi=\frac{1}{2}$ and they are of magnitude $\sigma=\frac{1}{2} Y_{2}=\frac{1}{2}$.

\section{Period 2: Optimal borrowing $b^{*}$ (in case of adverse income shock)}

In period 2, the household decides on its optimal borrowing in case it receives a negative income shock. It maximizes utility under the following budget constraints.

$$
\begin{aligned}
\max _{b} U\left(C_{2}\right) & +\beta U\left(C_{3}\right) \\
\text { s.t. } \quad & C_{2}=Y_{2}-\sigma+S_{1}+b=\frac{1}{2}+S_{1}+b \\
& C_{3}=Y_{3}-b(1+\rho)=1-b(1+\rho)
\end{aligned}
$$

It can be shown that optimal borrowing in period 2 (depending on the initial savings $\left.S_{1}\right)$ is as follows (see Appendix A.1 for details):

$$
b^{*}=\frac{1-\beta\left(\frac{1}{2}+S_{1}\right)-\rho \beta\left(\frac{1}{2}+S_{1}\right)}{(1+\beta)(1+\rho)}
$$

\section{Period 1: Optimal precautionary saving $S_{1}^{*}$}

In period 1, the households decides on its optimal amount of precautionary savings. Hereby, it maximizes the expected utility of its lifetime (depending on its anticipated optimal borrowing in period 2): 


$$
\begin{gathered}
\max _{S_{1}} U\left(C_{1}\right)+\pi \beta\left[U\left(C_{2 L}\right)+\beta U\left(C_{3 L}\right)\right]+(1-\pi) \beta\left[U\left(C_{2 H}\right)+\beta U\left(C_{3 H}\right)\right] \\
\text { s.t. } C_{1}=Y_{1}-S_{1}=1-S_{1} \\
C_{2 L}=Y_{2}+S_{1}-\sigma+b^{*}=\frac{1}{2}+S_{1}+b^{*} \\
C_{3 L}=Y_{3}-b^{*}(1+\rho)=1-b^{*}(1+\rho) \\
C_{2 H}=Y_{2}+S_{1}=1+S_{1} \\
C_{3 H}=Y_{3}=1
\end{gathered}
$$

When solving this simple optimization problem, I distinguish two cases: In the first case, the household anticipates that it would fully insure itself ex-post against income shocks by taking a consumer credit if the adverse income shock materializes. In the second case, the household anticipates that it would not take consumer credit if the adverse income shock materializes.

\section{Case 1: Optimal saving $S_{1}^{*}$ if optimal borrowing in period 2 is $b^{*}=\sigma$}

In this case, the household anticipates that it would fully insure itself ex-post by taking consumer credit if the income shock occurs. It can be shown that optimal saving $S_{1}^{*}$ in period 1 depending on optimal anticipated borrowing in period $2 b^{*}$ is as follows (see Appendix A.2 for details):

$$
S_{1}^{*} \mid\left(b^{*}=\sigma\right)=\frac{\beta-1}{\beta+1}
$$

Notice that $S_{1}^{*} \mid\left(b^{*}=\sigma\right)=0$ as household saving cannot be negative and the discount factor is not larger than one by definition $(\beta \leq 1)$. I.e. the household does not conduct precautionary saving if it anticipates that it takes consumer credit if the adverse income shock materializes.

\section{Case 2: Optimal saving $S_{1}^{*}$ if optimal borrowing in period 2 is $b^{*}=0$}

In this case, the household anticipates that it would not insure itself ex-post by taking consumer credit if the income shock occurs. It can be shown that optimal saving $S_{1}^{*}$ in period 1 depending on optimal borrowing in period 2 is as follows (see Appendix A.3 for 
details):

$$
S_{1}^{*} \mid\left(b^{*}=0\right)=\frac{-3+\frac{1}{2} \beta+\sqrt{12.25 \beta^{2}+\beta+1}}{2(2+2 \beta)}
$$

As pointed out in Appendix A.3, optimal precautionary saving is strictly positive $S_{1}^{*} \mid\left(b^{*}=\right.$ $0)>0$ for discount factors of $\beta^{*} \in\left(\frac{2}{3}, 1\right]$. I.e. the household does save ex-ante if it anticipates that it would not take consumer credit if the adverse income shock materializes and if its discount factor $\beta$ is sufficiently high.

\subsection{Empirical predictions}

In this section, I develop the empirical predictions on how time preferences and nonpecuniary costs can affect households' saving decisions directly and indirectly.

Hypothesis 1a: Higher non-pecuniary costs of taking credit ex-post lead to lower borrowing after the income shock materializes (details can be found in Appendix A.4), i.e.

$$
\frac{\partial b^{*}}{\partial \rho}<0
$$

Hypothesis 1b: A household that anticipates to take credit if the income shock materializes, will not save ex-ante. A household that anticipates not to take credit if the income shock materializes, will conduct precautionary saving ex-ante if its discount factor is sufficiently high $(\beta \geq \underline{\beta})$ (details can be found in Appendix A.5), i.e.

$$
S_{1}^{*}\left|\left(b^{*}=0\right)>0=S_{1}^{*}\right|\left(b^{*}=\sigma\right)
$$

Hypothesis 1b together with Hypothesis 1a imply that households that are faced with high non-pecuniary costs of taking credit if income shocks materialize are less likely to take consumer credit ex-post. Hence, they should be more likely to conduct precautionary saving ex-ante.

Hypothesis 2: The magnitude of precautionary savings is increasing in the discount factor (details can be found in Appendix A.6), i.e.

$$
\frac{\partial S_{1}^{*} \mid\left(b^{*}=0\right)}{\partial \beta}>0 \text { and } \frac{\partial S_{1}^{*} \mid\left(b^{*}=\sigma\right)}{\partial \beta}>0
$$


Hypothesis 2 implies that households with high discount factor should conduct more precautionary saving.

\subsection{Discussion}

In the theoretical analysis, I assumed that interest rates were the same and zero for all households. Besides, income risk was similar for all households (independent of their cultural exposure). This implies in particular that the risk of becoming unemployed is similar across all social groups and all households have similar access to social insurance (e.g. unemployment benefits).

My empirical research design accounts for these prerequisites by considering only households that are located within a small geographic scope. Hereby, it is reasonable to assume that interest rate differences do not exist due to arbitrage. Besides, households have the same access to social insurance and should face similar risk of unemployment.

Besides, in the empirical part I will only consider households that are non-retired and below 60 years old (which should be equivalent to households that live in period 1 or 2 in the model). 


\section{Background}

\subsection{Languages in Switzerland}

In Switzerland, there are four official languages: German, French, Italian and Romansh. According to the Federal Population Census in 2012, 64.9 percent of the resident population in Switzerland declared German as the main language, 22.6 percent speak French, 8.3 percent speak Italian and 0.5 percent speak Romansh $5^{5}$

[ Figure 1 ]

Figure 1 shows that the majority of residents in the North-eastern part of Switzerland speak predominantly German. People in the other parts of Switzerland speak predominantly a Romanic language (French, Italian or Romansh). The majority of the Swiss residents in the Western-part speak French while the majority of the residents of the Southern part speak Italian or Romansh. In most of the 26 cantons in Switzerland, there is only one major language: there are seventeen German-speaking cantons (e.g., Zurich, St. Gallen or Basel), four French-speaking (Geneva, Jura, Neuchatel and Vaud) and one Italian-speaking canton (Ticino). In addition, there are several cantons with more than one official language: the cantons Bern, Valais, and Fribourg are bilingual (French and German) and Graubünden is officially trilingual (German, Romansh, and Italian).

Figure 2 shows that the share of Romanic-speaking households per municipality changes depending on the distance to the language border. It can be easily seen from this figure that the share of Romanic-speaking households changes discontinuously from about .80 to .20 at the border. By definition there is no Romanic-speaking municipality on the German side of the language border (and vice versa).

\section{[ Figure 2]}

In Switzerland, most policies are set either at the federal or cantonal level. E.g. cantons have large discretion setting cantonal income and wealth tax rates. This is important as not income before taxes but net income affects household saving. Similarly, differences in net wealth could affect household saving. Besides, cantons set the curricula of primary

\footnotetext{
${ }^{5}$ Source: http://www.bfs.admin.ch/bfs/portal/en/index/themen/01/05/blank/key/sprachen.html, accessed on October 30th, 2014.
} 
and secondary schools. Hence, literacy and - in particular - financial literacy levels could vary across cantons - which might themselves affect household saving differentially. In my empirical analysis, I compare household decisions of households in the Romanicspeaking (French, Italian and Romansh) part to households in the German speaking part of Switzerland. As I intend to isolate cultural factors from differences in institutional, economic, topographic and weather conditions, it is crucial that I focus on multilingual cantons where the language border runs through them. For this reason, I focus in my empirical analysis on the four multilingual cantons (Bern, Fribourg, Graubünden and Valais). Besides, I compare only households located in the same canton.

\subsection{Differences in Household Saving}

While households in Switzerland have the same prerequisites and similar incentives to save a substantial amount of their income, there is substantial heterogeneity across income and language regions. Figure 3 shows the share of households that save at least $C H F 100$ per month by income levels and by language region in the four multilingual cantons (Bern, Fribourg, Graubünden, Valais) between 1999-2003. Low income (middle income, high income) households are households whose household income is in the lowest quartile (second \& third quartile, the highest quartile) of the income distribution in Switzerland per year.

\section{[ Figure 3 ]}

This figure illustrates two stylized facts: first, almost all households in the highest income group save at least $C H F 100$ per month irrespective of the language region they reside in. This share is substantially lower among low-income (around 60 percent) and among middle-income households (about 80 percent).

Second, the share of households that save seems to be more than 10 percentage points lower among households located in the Romanic-speaking part than among the ones in the German-speaking part of Switzerland.

In this paper, I investigate these heterogeneities in household saving. I focus on the subsample of low- and middle-income households and ask whether the observed differences between households in the Romanic- and German-speaking regions can be explained by their different cultural exposure. 


\section{Data, Identification, Estimation}

\subsection{Data}

The empirical analysis is based on the Swiss Household Panel. It is a longitudinal survey of households whose members represent the non-institutional population resident in Switzerland. It was first implemented in 1999 and consists of two parts: the first part is a household questionnaire that contains information on the composition of the household (e.g., household size, household income, etc.). In the second part of the survey, each household member is interviewed individually about his or her personal characteristics (age, gender, education, etc.) and whether he or she is responsible for the household finances. For each household, I only consider the person that is responsible for the household financial management ("household head") and match his/her responses to the information of the household he/she lives in. The survey was conducted by telephone interviews: the household interviews typically lasted 15 minutes (compared to about 35 minutes required for the individual interviews).

\section{Financial decisions and household characteristics}

The main dependent variable in my empirical analysis is Saving which indicates whether the household saves at least CHF 100 monthly. As shown in Appendix 2, only about 84 percent of my representative sample of low- and middle-income households save at least CHF 100 monthly - which implies that about one-fifth of the households do not save a minimum share of their income.

The share of non-savers is even higher when analyzing which households have a retirement savings account: as an alternative dependent variable, I employ Saving (Pension Fund) which indicates whether the household has a "pillar 3" pension fund to save for retirement. It turns out that the share of households without such an account is more than one-third (Appendix 2).

This paper not only elicits the saving decisions by households but also their expenditures. The variable Overspending indicates whether the household's expenses are higher than the household's income. As indicated in Appendix 2, about 8 percent of the households spend more than they earn. In addition, I employ the variable Payment arrears as a proxy for households' financial distress. This variable indicates whether the household has fallen into payment arrears within the preceding 12 months $!^{6}$ Appendix 2 shows that about 11

\footnotetext{
${ }^{6}$ Definitions of the variables are provided in Appendix 1. Summary statistics of all variables are
} 
percent of all households fall into payment arrears per year.

\section{Language per municipality, language region and distance to the language border}

I complement the household-level data of the Swiss Household Panel with further information on the municipality in which the household is located. In particular, I add information on the dominant language of each municipality: the binary variable $L_{i, m}$ indicates whether the majority of citizens in municipality $m$ in which the household $i$ resides speak a Romanic language (zero otherwise).

Hence, I define a language region as the set of municipalities that have the same dominant language (Romanic vs. German). Besides, I exploit the location of each municipality to calculate the walking distance to the language border in kilometers as proxied by the variable Distance. I provide further details on the calculation of these variables in Appendix B.

\section{Household covariates}

In addition, I employ several household and household head covariates in the empirical analysis: household variables are Household income, Household size. Besides, I use household head variables that serve as proxies for gender (Male), education (University), employment status (Employed, Self employed, Unemployed) and further socio-economic characteristics (Age, Swiss).

\section{Unemployment rates}

As existing research has shown that unemployment expectations can have an effect on households' saving decisions (Basten et al., 2012), I additionally control for regional unemployment rates. Therefore, I obtain information on regional unemployment rates per district and year from State Secretariat for Economic Affairs (SECO).

As my main dependent variable Saving is only available in the survey waves 1999 2003, I consider only survey respondents of these waves. Besides, I keep only households that have their primary residence in one of the four multilingual cantons (Bern, Fribourg, Graubünden and Valais). Moreover, I keep only households that are active in the labor provided in Appendix 2. 
market ${ }^{7}$ and that are in the lowest 75 percentile of the income distribution in Switzerland. My final sample consists of 643 households that represent the non-institutional low- and middle-income population in the four multilingual cantons (Bern, Fribourg, Graubünden, Valais) in 1999-2003.

\subsection{Identification}

To clarify the parameter of interest, I make use of the Potential Outcomes Framework. It enables me to define the causal effect before discussing the assignment mechanism and without specifying functional form and distributional assumptions..$^{8}$

The $\mathrm{N}=643$ households covered in my sample are indexed by $i=1, \ldots, N$. In the analysis, the treatment variable, $D_{i, m}$, can take on two different values: $D_{i, m}=1$ if household $i$ is located in a municipality $m$ in which a Romanic (French, Italian) language is the dominant language. Similarly, $D_{i, m}=0$ if household $i$ is located in a municipality $m$ in which German is the dominant language $9^{9}$ This definition of the treatment variable is mutually exclusive (as there is only one dominant language). Besides, it is exhaustive as I consider only municipalities where either French, German or Italian are the dominant languages.

I am interested in whether and how the exposure to a different dominant language group affects the intertemporal decisions of households - in particular their decision to save. The binary outcome variable $Y_{i, m}$ then takes on the value of one if the household $i$ saves at least $C H F 100$ monthly (zero otherwise). Given the definition of the treatment, two different potential outcomes exist: $Y_{i, m}(1)$ denotes the saving decision that would be realized if household $i$ was located in a Romanic-speaking municipality $m$. Similarly, $Y_{i, m}(0)$ denotes the saving decision that would be realized if household $i$ was located in a German-speaking municipality $m$. When analyzing the channels for the observed differences in household saving, the outcome variable $Y_{i, m}$ represents households' propensity to have smoked in the past or to take consumer credit in financial distress.

Simply relating household saving decisions $Y_{i, m}$ to the type of municipality $D_{i, m}$ can confounded by variables such as interest rates, inflation rates, unemployment risk, or access to financial services that might vary even within Switzerland. Not controlling for all

\footnotetext{
${ }^{7}$ I drop households whose household heads are retired.

$8^{8}$ see Imbens and Wooldridge (2009) for a more detailed discussion.

${ }^{9}$ I only observe the choice of the survey language but not the preferred language in daily life.
} 
factors might lead to biased point estimates. To overcome this problem I apply a Local Border Contrast ${ }^{10}$. Its main idea is to compare households that live on one side of the language border to households that are located on the other side. By considering only households that are located very close to the border, the importance of confounding variables decreases while differences in culture are preserved.

In order to implement this local border contrast, I define $E^{l}\left(Y_{i, m}\right)$ as the limit of the expectation of $Y_{i, m}$ on the Romanic-speaking (French, Italian) side of the language border: i.e., $E^{l}\left(Y_{i, m}\right)=\lim _{\epsilon \rightarrow 0-} E\left(Y_{i, m} \mid\right.$ Distance $\left._{i, m}=\epsilon\right)$. Similarly, I define $E^{r}\left(Y_{i, m}\right)$ as the limit of the expectation of $Y_{i, m}$ on the German-speaking side of the language border: i.e., $E^{r}\left(Y_{i, m}\right)=\lim _{\epsilon \rightarrow 0+} E\left(Y_{i, m} \mid\right.$ Distance $\left._{i, m}=\epsilon\right)$. The treatment effect of interest is as follows (Imbens and Lemieux, 2008):

$$
\tau_{S R D}=E\left[Y_{i, m}(1)-Y_{i, m}(0) \mid \text { Distance }_{i, m}=0\right]=E^{l}\left(Y_{i, m}\right)-E^{r}\left(Y_{i, m}\right)
$$

\section{Discussion}

The identification of this Local Average Treatment Effect relies on the assumption that the potential outcome variable is continuous in the running variable Distance $_{i, m}$, i.e.

$$
E\left(Y_{i, m}(1) \mid \text { Distance }_{i, m}=x\right) \text { and } E\left(Y_{i, m}(0) \mid \text { Distance }_{i, m}=x\right), \quad \forall x \approx 0
$$

This assumption means that two households located in two different but geographically close municipalities (that have the same dominant language) have essentially the same propensity to save. In particular, it implies that we would not expect to see a jump in household saving in a hypothetical thought experiment in which we moved a household together with its Romanic-speaking municipality located close to the border right across the language border to the German side (and vice versa).

This assumption would be violated if, at the language border, not only the dominant language per municipality changed but also factors that affect households' saving decisions

\footnotetext{
${ }^{10}$ see Hahn et al. (2001) for a detailed discussion.
} 
but are unaffected by the dominant language per municipality. In particular these could be economic conditions such as deposit interest rates, inflation rates or unemployment rates.11 I argue that this condition has to hold due to arbitrage. E.g. if deposit interest rates were actually higher in the Romanic-speaking part than in the German-speaking part, then households in the German-speaking part would start depositing money in banks in the Romanic-speaking part. They were able to do this as transaction costs close to the border are essentially close to zero. This increase in supply of deposits would decrease equilibrium interest rates in the Romanic-speaking part 12 .

Besides, this assumption would be violated if pre-determined household covariates that affect household saving changed discontinuously at the language border (e.g. gender of the household head). However, it does not imply that all households covariates have to be similar at the border. Instead, I expect some households covariates to be endogenous to the exposure to the dominant language: If, for example, time preferences actually differed across language regions, then we would expect different education and employment choices. Different savings rate could translate into different wealth levels over time.

\subsection{Estimation}

I estimate this effect using a linear parametric specification (similar to Eugster et al. (2011)).

$$
Y_{i, m}=\alpha+\delta L_{i, m}+\beta_{l 1} L_{i, m} \text { Distance }_{i, m}+\beta_{r 1} \text { Distance }_{i, m}+X_{i, m}^{\prime} \gamma+\epsilon_{i, m},
$$

where $L_{i, m}$ is a binary variable that takes on the value of 1 if the majority of the municipality in which the household $i$ resides speaks a Romanic language (zero otherwise). $X_{i, m}$ is a vector of variables that capture differences between households and municipalities: it contains canton dummy variables and socio-economic household characteristics. I control for different (linear and non-linear) spatial trends using the Distance $_{i, m}$ variables. Here, the parameter $\beta_{r 1}$ estimates the spatial trend in the outcome variable on the German side of the language border. Similarly, $\beta_{l 1}$ measures the spatial trend in the outcome variable on the Romanic speaking side of the language border that is different from the trend on the German side. Since $E\left[Y_{i, m} \mid\right.$ Distance $\left._{i, m}=0, L_{i}=1\right]=\alpha+\delta+X_{i}^{\prime} \gamma$ and

\footnotetext{
${ }^{11}$ It is important to understand that this assumption does allow for differences between distant parts of the two language regions but not for differences across language regions close to the border.

${ }^{12}$ Similar arguments can be made for unemployment rates or inflation rates
} 
$E\left[Y_{i, m} \mid\right.$ Distance $\left._{i, m}=0, L_{i}=0\right]=\alpha+X_{i}^{\prime} \gamma$, the parameter of interest is the estimate of $\delta$.

Given the relatively low number of survey respondents that are located in the four multilingual cantons in my sample, I decide to estimate equation 17 including only the households that are located within 50 kilometers from the language border (similar to Eugster et al. (2011)). I show that the results are robust to varying this ad-hoc bandwidth within a range of $30 \mathrm{~km}$ to $70 \mathrm{~km}$. I estimate this linear regression using ordinary least squares while clustering the standard errors two-way on the household and municipality level.

\section{$5 \quad$ Language and Household Saving}

\subsection{Household Characteristics \& Decisions by Language Region}

In this section, I document that the low-and middle-income households located in the Romanic-speaking part are less likely to save and are more likely to spend more than they earn. Besides, I show that the households that I consider in my sample are similar along major dimensions of household characteristics relevant for the saving decision.

\section{[ Table 1 ]}

Panel A of Table 1 presents a univariate analysis comparing the individual saving decisions of non-retired low- and middle-income households resident in the Romanic-speaking part of Switzerland to the ones living in the German-speaking part. It only considers households located within $50 \mathrm{~km}$ from the language border in the four multilingual cantons (Bern, Fribourg, Graubünden, Valais) in 1999-2003. The table shows that the propensity to save at least CHF 100 is about 12 percentage points higher among households resident in the German-speaking part (89 percent) than among households in the Romanic-speaking part (77 percent). This difference is statistically significant on all conventional significance levels. It is qualitatively similar when considering the share of households that saves explicitly for retirement by using a "pillar 3" pension fund (differences of 11 percentage points). Besides, households in the Romanic-speaking part seem to be about 6 percentage points more likely to spend more than they earn. 
While the households I consider in the sample differ with respect to their intertemporal financial decisions, they are similar along major dimensions. Panel B of Table 1 shows that there are no differences in Household income or Household size. Furthermore, also the household heads differ not at all or only marginally with respect to major socio-economic characteristics (Male, University, Age, Swiss, Employed, Self employed, Unemployed).

\subsection{Local Border Contrast: Household Saving}

In this section, I show that the univariate differences in household saving are robust to more rigorous empirical testing. Figure 4 illustrates the share of households that save at least $C H F 100$ per month depending on the distance to the language border. First, it can be seen that the share of households that save more than CHF 100 is substantially lower in the Romanic-speaking part than in the German-speaking part. Second, there is evidence of a spatial trend in household saving: households in the Romanic-speaking that are located far away from the language border are slightly more likely to save than their counterparties close to the border. Similarly, households in the German-speaking part that are distant from the language border are less likely to save than households close to the border. Third, there is graphical evidence that share of households that save at least CHF 100 jumps discontinuously at the language border where the travel distance is zero.

\section{[ Figure 4 ]}

I am interested in whether the size of this discontinuity of household saving at the language border is economically meaningful and statistically different from zero. Therefore, I implement the regression in equation 17 and report the point estimate of the parameter $\delta$. This estimate can be interpreted as the effect of a change in the language region on households' saving behavior at the language border.

Panel A of Table 2 reports my baseline estimates in my preferred sample of non-retired low- and middle-income households located within $50 \mathrm{~km}$ from the language border in the four multilingual cantons (Bern, Fribourg, Graubünden, Valais). The first column shows the effect of language region on household saving is about 12 percentage points (without controlling for spatial trends or any household or regional characteristics). When controlling for linear spatial trends, canton fixed effects and socio-economic household characteristics (Household income (natural logarithm), Household size, Male, University, Age, Swiss, Employed, Self employed, Unemployed), this gap increases to 26 percentage 
points (column 2). The magnitude and statistical significance remains qualitatively similar after controlling for regional unemployment rates (columns 3 \& 5) and additionally controlling for quadratic spatial trends (columns $4 \& 5){ }^{13}$

In unreported robustness checks, I show that these results are robust to changing the bandwidths by 20 kilometers in both directions. Besides, the results remain qualitatively similar when additionally controlling for the main religion of the household head (catholic, protestant or other).

\section{[ Table 2 ]}

Overall, there is strong empirical evidence that the exposure to certain language groups affects households' saving behavior. Appendix 3 shows this gap persists when considering households' decision to have a "pillar 3" pension fund (Panel A) and to consume excessively (Panel B).

\footnotetext{
${ }^{13}$ The results are robust to the inclusion of higher order distance polynomials.
} 


\section{Possible Channels}

In this paper, I argue that different distributions of time preferences and norms of taking formal or informal consumer credit in financial distress can affect a households' decision to save. In this section, I ask whether these preferences and norms actually differ across language regions and whether these differences are consistent with the observed differences in household saving.

\subsection{Time Preferences}

Household heads might differ with respect to their individual discount rates. Higher discount rates might imply that households are more likely to consume today and shift less wealth to the future: i.e., they save more (Sutter et al., 2013). It is a natural question to ask whether Romanic-speaking households save less because they simply have higher discount rates and are more impatient.

To answer this question, I employ past tobacco consumption as a proxy for individual impatience and discount rates. Several existing studies have shown that there is a direct relationship between past smoking behavior and individual impatience (Chabris et al. (2008), Khwaja et al. (2006)). The 2010 \& 2011 waves of the Swiss Household Panel ask household heads whether they had "ever smoked cigarettes, cigars or pipe?". The variable Tobacco smoked takes on the value of one if the household head responds with Yes to this question (zero if $\mathrm{No}$ ).

Again, I test for significant differences of this variable across language regions. As this variable is only available in the survey waves of 2010 \& 2011, I use the sample of lowand middle-income households located within $50 \mathrm{~km}$ from the language border in the four multilingual cantons (Bern, Fribourg, Graubünden, Valais) in these waves.

The results of Table 3 (Panel A) show that the share of household heads that has ever smoked tobacco is substantially higher in the Romanic-speaking part (0.65) than in the German-speaking part (0.54). The difference of 11 percentage points is economically meaningful and statistically significant on all conventional significance levels. After controlling for linear spatial trends (and household control variables and canton and year fixed effects), the Romanic-German gap is increases in magnitude (15 - 17 percentage points) 
and is borderline statistically significant at the ten percent level. The magnitude of the point estimates of this language gap increases slightly to 33 percentage points after controlling for quadratic spatial trends.

Overall, there is evidence for a discontinuity of my proxy of impatience. These results are similar when changing the ad-hoc bandwidths by 20 kilometers.

\section{[ Table 3 ]}

\subsection{Formal or informal consumer credit in financial distress}

Households face uncertainty regarding future adverse income and expenditure shocks (e.g., due to unemployment, lower bonus payments or unanticipated medical expenses due to illness). Ex-ante insurance against these events is often infeasible if insurance markets are incomplete and do not offer insurance for all contingencies. Besides, ex-ante insurance might often not be expedient if the offered insurance premiums are not actuarially fair. If this is the case, households might conduct higher ex-ante precautionary savings to accumulate enough wealth that might serve as a buffer against these negative shocks. Alternatively, households may rely on their informal networks of family and friends to share the risks of these adverse shocks and smooth consumption. I.e. they may take Informal credit from their networks of family and friends once income shocks materialize and the household is in financial distress (Ortigueira and Siassi (2013), Bloch et al. (2008), Hayashi et al. (1996), Ligon (1998)). Alternatively, these households might take Formal credit from financial institutions to smooth consumption.

In this section, I ask whether Romanic-speaking households are less likely to save as they expect to be helped by their informal networks if adverse income or expenditure shocks materialize. I argue that the households I compare in the empirical analysis are faced with similar conditions on the formal insurance market as (i) they are similar regarding all major socio-economic characteristics and (ii) are located in geographic proximity within the same canton. Hence, lower savings among households could be rooted in different norms of taking Formal credit or Informal credit in financial distress.

I suggest an indirect test for this hypothesis by pointing out differences in how households resolve financial distress: In the survey, the respondents are asked whether they are in financial distress and how they resolve it. In particular, they are asked whether they react to these financial problems "(...) by borrowing from relatives or friends" or "(...) by 
borrowing from banks". In the following analysis I rely on the binary variable Informal credit which takes on the value of one if the household head responded to borrow from family members or friends in case of financial problems (zero otherwise) and Formal credit which takes on the value of one if the household head responded to borrow from banks (zero otherwise).

As these questions are asked in each survey wave, I consider all households located within $50 \mathrm{~km}$ from the language border in the four multilingual cantons (Bern, Fribourg, Graubünden, Valais) over time (1999-2012). Among these households, 342 households fall into payment arrears at some point between 1999 and 2012. In total, there are 789 incidences of financial distress.

Panel A of Table 4 illustrates that there is some evidence that households in the Romanic-speaking part are more likely to rely on Informal credit once they fall into payment arrears: A simple mean comparison does not reveal any statistically significant differences between language regions (column 1). Yet, controlling for linear spatial trends (columns $2 \& 3$ ) and additionally controlling for quadratic spatial trends (columns 4 \& 5), there is evidence that households in the Romanic-speaking parts are about 16 - 30 percentage points more likely to take informal credit. Again, these point estimates remain qualitatively similar when decreasing the bandwidth to only 30 kilometers.

In Panel B of Table 4, I test for differences in relying on Formal credit when falling into payment arrears: A simple mean comparison only reveals a marginally higher propensity to take formal credit among the households in the Romanic-speaking part (column 1). Controlling for linear spatial trends (columns $2 \& 3$ ) and additionally controlling for quadratic spatial trends (columns $4 \& 5$ ), this difference increases slightly in economic magnitude but remains largely statistically insignificant.

[ Table 4 ]

I conclude that there are some differences in how Romanic-speaking households resolve financial distress compared to German-speaking households. There is evidence that the former are more likely to rely on an informal network of family and friends if they fall into payment arrears compared to the latter. Given that the households are similar along 
relevant dimensions and assuming that there are not any differences in the supply of financial products, I interpret this as evidence for higher risk-sharing among Romanic-speaking households. A higher degree of risk-sharing might ultimately lead to lower precautionary saving (Ortigueira and Siassi (2013)). In contrast, I do not find evidence that households in the Romanic-speaking part are more likely to rely on formal credit once they fall into payment arrears.

\subsection{Validity of the Research Design}

In this section, I run a battery of tests that verify the validity of my research design (as suggested by Imbens and Lemieux (2008)). First, I test for differences in household characteristics across language regions. The mean-comparisons presented in Panel B of Table 2 already indicated that the households did not differ along most of the observable household characteristics that could be relevant for the households' saving decision. In addition, I provide a formal test of the discontinuity of all relevant household characteristics at the language border. As illustrated in Appendix 4, I do not find evidence for discrete jumps of most household covariates at the border.

Second, I test whether there are discontinuities in household saving within the same language region. As suggested by Imbens and Lemieux (2008), I employ two placebo tests in which I take the median distance on both side of the language regions as alternative cutoff points. As illustrated in Appendix 5, I do not find evidence for discrete jumps of household saving when applying these placebo tests.

Third, I analyze the residuals of the main regression shown in column 2 of Table 2 Panel A. If households in the Romanic-speaking part differed in unobservable characteristics from households in the German-speaking part, the residuals of this regression should be

systematically different. Figure 5 in the Appendix shows that this is not the case: The residuals are scattered randomly around zero on both sides of the language border.

Last, I apply an alternative identification strategy. Instead of using the language region as the treatment variable, I estimate the effect of language group membership on the propensity to save. Hereby, I control for all observable household and regional characteristics that I believe can determine the individual saving decision and could be correlated with the language spoken. I find that Romanic-speaking households are about 11 to 12 percentage points less likely to save at least $C H F 100$ per month and are 10 to 11 percentage points more likely to spend more money than they earn (Appendix 6). 


\section{Conclusion}

In this paper, I analyze the role of culture for households' intertemporal financial decisions. In particular, I examine whether the exposure to specific language groups affects the households' decision to save and overspend. Besides, I elicit potential channels of how language group membership affects these decisions.

Hereby, I exploit within-country variation of historically determined language group memberships in Switzerland. I compare the financial decisions of a representative and homogenous sample of low- and middle income households that are similar on all relevant socio-economic characteristics on the German-speaking side of the language border to the ones on the Romanic-speaking (French, Italian, Romansh) side. To do so, I implement a spatial regression discontinuity design in which I am able to isolate cultural differences of a representative sample of the population from differences in economic (e.g., business cycles, interest rates and inflation), institutional (e.g., pension systems, education) and geographic conditions (e.g., access to financial services).

The analysis is based on data from the Swiss Household Panel. This survey includes a wide range of socio-economic household characteristics such as income, the employment status and the exact location of each household. Furthermore, it includes characteristics of the person responsible for the management of household finances ("household head") (in particular her age, gender, education, etc.), her preferred language spoken (French, Italian or German) and variables that have been shown to be good proxies for time preferences (e.g., past tobacco consumption). I complement these data with detailed information on language and religious regions within Switzerland.

I document that households in the Romanic-speaking part are more than 12 percentage points less likely to save and 6 percentage points more likely to spend excessively. These results are robust to more formal testing when implementing the local border contrast. I find evidence that stronger relevance of informal networks of friends and family and higher time discount rates among Romanic-speaking households can explain these differences. 


\section{References}

Agarwal, S. and R. Hauswald (2010). Distance and Private Information in Lending. Review of Financial Studies, 1-32.

Angelucci, M. and G. De Giorgi (2009). Indirect Effects of an Aid Program: How Do Cash Transfers Affect Ineligibles' Consumption? American Economic Review 99(1), 486-508.

Basten, C., A. Fagereng, and K. Telle (2012). Saving and portfolio allocation before and after job loss. Working Paper (672).

Bauer, T. K. and M. G. Sinning (2011). The savings behavior of temporary and permanent migrants in Germany. Journal of Population Economics 24, 421-449.

Bloch, F., G. Genicot, and D. Ray (2008). Informal insurance in social networks. Journal of Economic Theory 143(1), 36-58.

Börsch-Supan, A., A. Reil-held, and D. Schunk (2008). Saving incentives, old-age provision and displacement effects: evidence from the German pension reform. Journal of Pension Economics and Finance 7, 295-319.

Bover, O., J. M. Casado, S. Costa, P. D. Caju, Y. McCarthy, E. Sierminska, P. Tzamourani, E. Villanueva, and T. Zavadil (2014). The distribution of debt across euro area countries: the role of individual characteristics, institutions and credit conditions. Deutsche Bundesbank Discussion Paper (1).

Breuer, W. and A. J. Salzmann (2012). National Culture and Household Finance. Global Economy and Finance Journal (5).

Brown, J. R., Z. Ivkovic, P. A. Smith, and S. Weisbenner (2008). Neighbors Matter: Causal Community Effects and Stock Market Participation. Journal of Finance LXIII(3), 1509-1531.

Brown, M., B. Guin, and S. Morkötter (2014). Deposit Withdrawals from Distressed Commercial Banks. Working Paper.

Carroll, C., J. Overland, and D. N. Weil (2000). Saving and Growth with Habit Formation. American Economic Review $90(3)$, 341-355. 
Carroll, C., B.-K. Rhee, and C. Rhee (1994). Are there cultural effects on saving? Some cross-sectional evidence. Quarterly Journal of Economics 3, 685-699.

Carroll, C. and L. H. Summers (1987). Why Have Private Savings Rates in the United States and Canada Diverged? Journal of Monetary Economics 20, 249-279.

Chabris, C., D. Laibson, C. Morris, J. Schuldt, and D. Taubinsky (2008). Individual laboratory-measured discount rates predict field behavior. Journal of Risk and Uncertainty 37, 237-269.

Chen, K. (2013). The Effect of Language on Economic Behavior: Evidence from Savings Rates, Health Behaviors, and Retirement Assets. American Economic Review 103(2), 690-731.

Christelis, D., M. Ehrmann, and D. Georgarakos (2013). Exploring Differences in Household Debt across Euro Area Countries and the US. Working Paper, 1-38.

Christelis, D., D. Georgarakos, and M. Haliassos (2011). Stockholding: Participation, location, and spillovers. Journal of Banking and Finance 35, 1918-1930.

Degryse, H. and S. Ongena (2005). Distance, Lending Relationships, and Competition. Journal of Finance 60(1), 231-266.

Duflo, E., W. Gale, J. Liebman, P. Orszag, and E. Saez (2006). Saving Incentives for Low- and Middle-Income Families: Evidence from a Field Experiment with H\&R Block. Quarterly Journal of Economics (November), 1311-1346.

Duflo, E. and E. Saez (2002). Participation and investment decisions in a retirement plan: the influence of colleagues choices. Journal of Public Economics 85, 121-148.

Engen, E. M. and J. Gruber (2001). Unemployment insurance and precautionary saving. Journal of Monetary Economics 47, 545-579.

Eugster, B., R. Lalive, A. Steinhauer, and J. Zweimüller (2011). The Demand for Social Insurance: Does Culture Matter? Economic Journal 121, 413-448.

Fay, S., E. Hurst, and M. White (2002). An Empirical Analysis of Personal Bankruptcy and Delinquency. American Economic Review 92(3), 706-718.

Fernández, R. (2011). Does Culture Matter? (1A ed.), Volume 1. Elsevier. 
Georgarakos, D., M. Haliassos, and G. Pasini (2014). Household Debt and Social Interactions. Review of Financial Studies, forthcoming.

Gross, D. and N. Souleles (2002). An Empirical Analysis of Personal Bankruptcy and Delinquency. Review of Financial Studies 15(1), 319-347.

Guiso, L., P. Sapienza, and L. Zingales (2006). Does Culture Affect Economic Outcomes? Journal of Economic Perspectives 20(2), 23-48.

Guiso, L., P. Sapienza, and L. Zingales (2013). The Determinants of Attitudes toward Strategic Default on Mortgages. Journal of Finance LXVIII(4), 1473-1515.

Hahn, J., P. Todd, and W. V. der Klaauw (2001). Identification and Estimation of Treatment Effects with a Regression-Discontinuity Design. Econometrica 69(1), 201-209.

Haliassos, M., T. Jansson, and Y. Karabulut (2014). Incompatible European Partners? Cultural Predispositions and Household Financial Behavior. Working Paper, 1-65.

Hayashi, F., J. Altonji, and L. Kotlikoff (1996). Risk-Sharing between and within Families. Econometrica 64(2), 261-294.

Hong, H., J. D. Kubik, and J. C. Stein (2004). Social Interaction and Stock-Market Participation. Journal of Finance LIX(1), 137-163.

Imbens, G. M. and T. Lemieux (2008). Regression Discontinuity Designs: A guide to practice. Journal of Econometrics 142, 615-635.

Imbens, G. M. and J. M. Wooldridge (2009). Recent Developments in the Econometrics of Program Evaluation. Journal of Economic Literature 47(1), 5-86.

Kaustia, M. and S. Knüpfer (2012). Peer performance and stock market entry. Journal of Financial Economics 104, 321-338.

Khwaja, A., F. Sloan, and M. Salm (2006). Evidence on preferences and subjective beliefs of risk takers: The case of smokers. International Journal of Industrial Organization 24 , 667-682.

Kimball, M. (1990). Precautionary Savings in the Small and in the Large. Econometrica $58(1), 53-73$. 
Kuhn, P., P. Kooreman, A. Soetevent, and A. Kapteyn (2011). The Effects of Lottery Prizes on Winners and Their Neighbors: Evidence from the Dutch Postcode Lottery. American Economic Review 101, 2226-2247.

Ligon, E. (1998). Risk Sharing and Information in Village Economies. Review of Economic Studies 65, 847-864.

Luttmer, E. F. (2005). Neighbors as Negatives: Relative Earnings and Well-Being. Quarterly Journal of Economics 120(3), 963-1002.

Ortigueira, S. and N. Siassi (2013). How important is intra-household risk sharing for savings and labor supply? Journal of Monetary Economics 60, 650-666.

Piracha, M. and Y. Zhu (2012). Precautionary savings by natives and immigrants in Germany. Applied Economics 44(21), 2767-2776.

Sinning, M. G. (2011). Determinants of savings and remittances: empirical evidence from immigrants to Germany. Review of Economics of the Household 9(1), 45-67.

Sutter, M., S. Angerer, D. Glätzle-Rützler, and P. Lergetporer (2014). The effects of language on children's intertemporal choices. Working Paper.

Sutter, M., M. Kocher, D. Glätzle-Rützler, and S. Trautmann (2013). Impatience and Uncertainty: Experimental Decisions Predict Adolescents' Field Behavior. American Economic Review 103(1), 510-531. 


\section{A Solution to the Stylized Model}

\section{A.1 Household borrowing decision in $\mathrm{t}=2$}

The following first-order condition has to hold:

$$
F O C: \frac{1}{1+S_{1}-\sigma+b}+\beta \frac{(1+\rho)}{1-b(1+\rho)}=0
$$

which is equivalent to:

$$
1-b(1+\rho)=\beta(1+\rho)\left(1+S_{1}-\sigma+b\right)
$$

Solving for $b$ gives optimal borrowing $b^{*}$ depending on $S_{1}$.

$$
b^{*}=\frac{1-\beta\left(\frac{1}{2}+S_{1}\right)-\rho \beta\left(\frac{1}{2}+S_{1}\right)}{(1+\beta)(1+\rho)}
$$

\section{A.2 Household saving decision in $t=1$ if optimal borrowing in period 2 is $b^{*}=\sigma$}

In case of full ex-post insurance, the following first-order condition has to hold:

$$
F O C:-\frac{1}{1-S_{1}}+\pi \beta \frac{1}{1+S_{1}}+(1-\pi) \beta \frac{1}{1+S_{1}}=0
$$

which is equivalent to:

$$
-\frac{1}{1-S_{1}}+\frac{\beta}{1+S_{1}}=0
$$

Solving for $S_{1}$ gives optimal precautionary saving $S_{1}^{*}$.

$$
S_{1}^{*} \mid\left(b^{*}=\sigma\right)=\frac{\beta-1}{\beta+1}
$$

As $\beta \leq 1$, optimal precautionary saving $S_{1}^{*} \mid\left(b^{*}=\sigma\right)$ is zero as saving cannot be negative (by definition). 


\section{A.3 Household saving decision in $\mathrm{t}=1$ if optimal borrowing in period 2 is $b^{*}=0$}

The following first-order condition has to hold:

$$
F O C:-\frac{1}{1-S_{1}}+\pi \beta \frac{1}{1+S_{1}-\sigma}+(1-\pi) \beta \frac{1}{1+S_{1}}=0
$$

Assuming income shocks are of magnitude $\sigma=\frac{1}{2}$ and the probability of income shocks is $\pi=\frac{1}{2}$, this is equivalent to:

$$
2\left[\left(\frac{1}{2}+S_{1}\right)\left(1+S_{1}\right)\right]=\beta\left(1-S_{1}\right)\left[\left(1+S_{1}\right)+\left(\frac{1}{2}+S_{1}\right)\right]
$$

Solving for $S_{1}$ gives optimal precautionary saving $S_{1}^{*}$ :

$$
\begin{aligned}
S_{1}^{*} \mid\left(b^{*}=0\right) & =\frac{-3+\frac{1}{2} \beta+\sqrt{\left(3-\frac{1}{2} \beta\right)^{2}-4(2+2 \beta)\left(1-\frac{3}{2} \beta\right)}}{2(2+2 \beta)} \\
& =\frac{-3+\frac{1}{2} \beta+\sqrt{12.25 \beta^{2}+\beta+1}}{2(2+2 \beta)}
\end{aligned}
$$

As $\beta$ is non-negative (by definition), $\sqrt{12.25 \beta^{2}+\beta+1}$ is a real number. Besides, the denominator of equation 27 is strictly positive. Hence, optimal precautionary saving is strictly positive $S_{1}^{*} \mid\left(b^{*}=0\right)>0$ if the following inequality holds:

$$
12.25 \beta^{2}+\beta+1>\left(3-\frac{1}{2} \beta\right)^{2}
$$

This inequality is equivalent to:

$$
12 \beta^{2}+4 \beta-8>0
$$

Solving for $\beta$ yields the critical discount factor $\beta^{*}$ :

$$
\beta^{*}>\frac{2}{3}
$$

For households with discount factors of $\beta^{*} \in\left(\frac{2}{3}, 1\right]$, optimal precautionary saving is positive (if anticipated optimal borrowing in period 2 is zero $\left(b^{*}=0\right)$ ). 


\section{A.4 Hypothesis 1a}

From Appendix A.1 we know that:

$$
b^{*}=\frac{1-\beta\left(\frac{1}{2}+S_{1}\right)-\rho \beta\left(\frac{1}{2}+S_{1}\right)}{(1+\beta)(1+\rho)}
$$

Taking the partial derivative with respect to $\rho$ yields:

$$
\frac{\partial b^{*}}{\partial \rho}=\frac{-\beta\left(\frac{1}{2}+S_{1}\right)(1+\beta)(1+\rho)-\left[1-\beta(1+\rho)\left(\frac{1}{2}+S_{1}\right)\right](1+\beta)}{[(1+\beta)(1+\rho)]^{2}}
$$

which is equivalent to:

$$
\frac{\partial b^{*}}{\partial \rho}=\frac{(1+\beta)(1+\rho)\left[-\beta\left(\frac{1}{2}+S_{1}\right)+\beta\left(\frac{1}{2}+S_{1}\right)\right]-(1+\beta)}{[(1+\beta)(1+\rho)]^{2}}
$$

which can be simplified to:

$$
\frac{\partial b^{*}}{\partial \rho}=\frac{-(1+\beta)}{[(1+\beta)(1+\rho)]^{2}}<0
$$

It can be easily seen that $\frac{\partial b^{*}}{\partial \rho}$ is negative as $\beta$ is non-negative (by definition).

\section{A.5 Hypothesis $1 \mathrm{~b}$}

We know from Appendix A.2 that household precautionary saving is $S_{1}^{*} \mid\left(b^{*}=\sigma\right)=\frac{\beta-1}{\beta+1}=0$ (if optimal borrowing in period 2 is $b^{*}=\sigma$ ).

Besides, we know from Appendix A.3 that household precautionary saving is $S_{1}^{*} \mid\left(b^{*}=\right.$ $0)=\frac{-3+\frac{1}{2} \beta+\sqrt{12.25 \beta^{2}+\beta+1}}{2(2+2 \beta)}>0, \forall \beta \in\left(\frac{2}{3}, 1\right]$ (if optimal borrowing in period 2 is $b^{*}=0$ ).

Hence, it follows that:

$$
S_{1}^{*}\left|\left(b^{*}=0\right)>0=S_{1}^{*}\right|\left(b^{*}=\sigma\right), \forall \beta \in\left(\frac{2}{3}, 1\right]
$$

\section{A.6 Hypothesis 2}

I consider the two cases separately: 
Case 1: $\frac{\partial S_{1}^{*} \mid\left(b^{*}=\sigma\right)}{\partial \beta}$

Household precautionary saving is increasing in $\beta$ if optimal borrowing in period 2 is $b^{*}=\sigma$. This can be seen from the first partial deriviative with respect to $\beta$ :

$$
\frac{\partial S_{1}^{*} \mid\left(b^{*}=\sigma\right)}{\partial \beta}=\frac{2}{(1+\beta)^{2}}>0
$$

This inequality holds.

Case 2: $\frac{\partial S_{1}^{*} \mid\left(b^{*}=0\right)}{\partial \beta}$

Household precautionary saving is increasing in $\beta$ if optimal borrowing in period 2 is $b^{*}=0$ :

$$
\frac{\partial S_{1}^{*} \mid\left(b^{*}=0\right)}{\partial \beta}>0
$$

We know from Appendix A.3 that optimal precautionary saving if optimal borrowing in period 2 is $b^{*}=0$ is:

$$
S_{1}^{*} \mid\left(b^{*}=0\right)=\frac{-3+\frac{1}{2} \beta+\sqrt{12.25 \beta^{2}+\beta+1}}{2(2+2 \beta)}
$$

Again, we can check the sign of the first partial derivative with respect to $\beta$ :

$$
\frac{\partial S_{1}^{*} \mid\left(b^{*}=0\right)}{\partial \beta}=\frac{\left[\frac{1}{2}+\frac{1}{2} a^{-.5}(24.5 \beta+1)\right] \cdot(4+4 \beta)-\left[-3+\frac{1}{2} \beta+\sqrt{a}\right] \cdot 4}{(4+4 \beta)^{2}}
$$

where $a=12.25 \beta^{2}+\beta+1$. Notice that $\frac{\partial S_{1}^{*} \mid\left(b^{*}=0\right)}{\partial \beta}>0$ if:

$$
\left[\frac{1}{2}+\frac{1}{2} a^{-.5}(24.5 \beta+1)\right] \cdot(4+4 \beta)-\left[-3+\frac{1}{2} \beta+\sqrt{a}\right] \cdot 4>0
$$

This is equivalent to:

$$
\left(\sqrt{a}\left[10-\frac{1}{2} \beta\right]-4\right)+\frac{1}{2}[24.5 \beta+1][4+4 \beta]>0
$$

Showing that this inequality is true is fairly simple: 
First, as $\beta$ is strictly positive by assumption, we know that:

$$
\frac{1}{2}[24.5 \beta+1][4+4 \beta]>0, \quad \forall 0<\beta \leq 1
$$

Second, as $\beta$ is strictly positive, we also know that $a>1$. It follows that:

$$
\left(\sqrt{a}\left[10-\frac{1}{2} \beta\right]-4\right)>0, \quad \forall 0<\beta \leq 1
$$

Hence, optimal precautionary saving is increasing in $\beta$ if optimal borrowing in period 2 is $b^{*}=0$. 


\section{B Data Appendix}

In this section, I provide further details on the calcuation and sources of the language variables. The data relies to a large extent on data used by Eugster et al. (2011).

\section{B.1 Dominant language per municipality $L_{i, m}$}

The Swiss Population Census in 2000 by the Federal Statistical Office provides information on each person's main language spoken at home. I use this information to determine the major language of each municipality. The variable $L_{i, m}$ takes on the value of one if household $i$ lives in a municipality $m$ where more than $50 \%$ of the population prefers to speak a Romanic language at home (zero otherwise) 14

\section{B.2 Language region}

I define a Language region to be the set of municipalities that have the same major language. E.g. the Romanic-speaking region of Switzerland includes all municipalities in which the majority of the population speaks a Romanic language. Similarly, the Germanspeaking region of Switzerland includes all municipalities in which the majority of the population speaks German. As it can be seen in Figure 1, there are several enclaves, i.e. German-speaking municipalities entirely surrounded by Romanic-speaking municipalities. In this baseline definition, these German-speaking municipalities are part of the Germanspeaking language region. This definition is important for the empirical strategy that I point out in section 4 .

\section{B.3 Distance to the language border}

To calculate the distance to the language border I rely on data on the driving distance in kilometers between any pair of municipalities in Switzerland 15 As there is no official definition of the language border that separates the language regions, I define border municipalities as the Romanic-speaking municipalities whose closest neighboring municipality is a German-speaking municipality. By definition, these Romanic-speaking border municipalities are assigned distance values of zero $\left(\right.$ Distance $_{i, m}=0$ ). For each of the remaining municipalities, I then calculate the distance between the municipality and the

\footnotetext{
${ }^{14}$ I rely on year 2000 data assuming that the composition of the language speakers did not change tremendously over time.

${ }^{15}$ The matrix of all distance pairs was obtained from the online platform search.ch.
} 
closest Romanic-speaking border municipality. The Distance $_{i, m}$ variable then takes on values greater than zero. 
Figure 1. Language Regions in Switzerland

This figure shows the main language dependending on regions in Switzerland. Orange illustrates Romanic-speaking regions, dark navy illstrates German-speaking regions (in 2000).

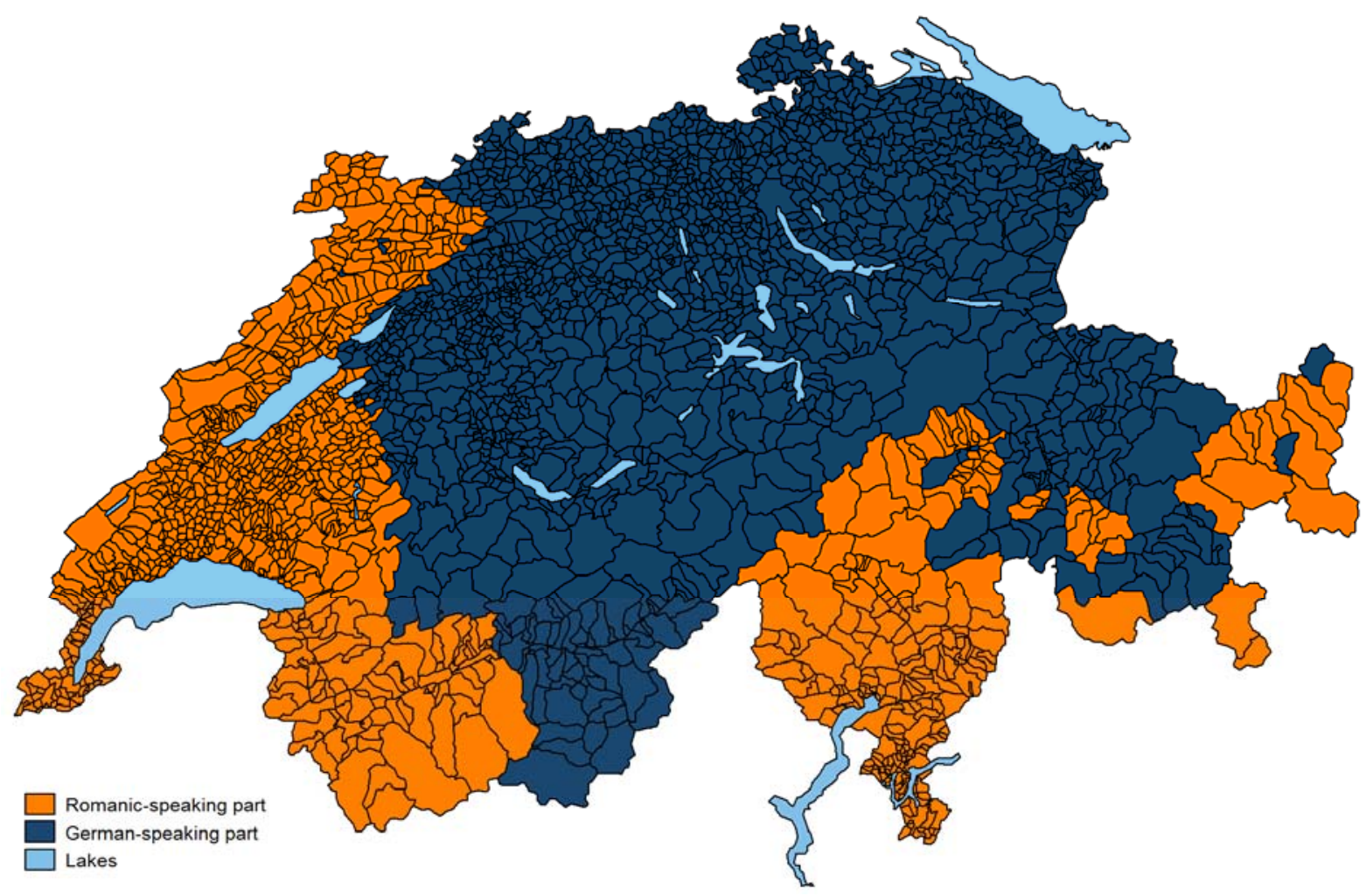


Figure 2. Romanic speakers and language region

This figure shows the share the share of Romanic (French, Italian) speaking households depending on the distance to the language border (as indicated by the dots). The vertical line indicates the language border as detailed in the text. Dots left to (right to) the vertical line indicate the share Romanic-speaking households per $10 \mathrm{~km}$ buckets in the Romanic-speaking part (German-speaking part).

Source: Swiss Household Panel (1999-2012).

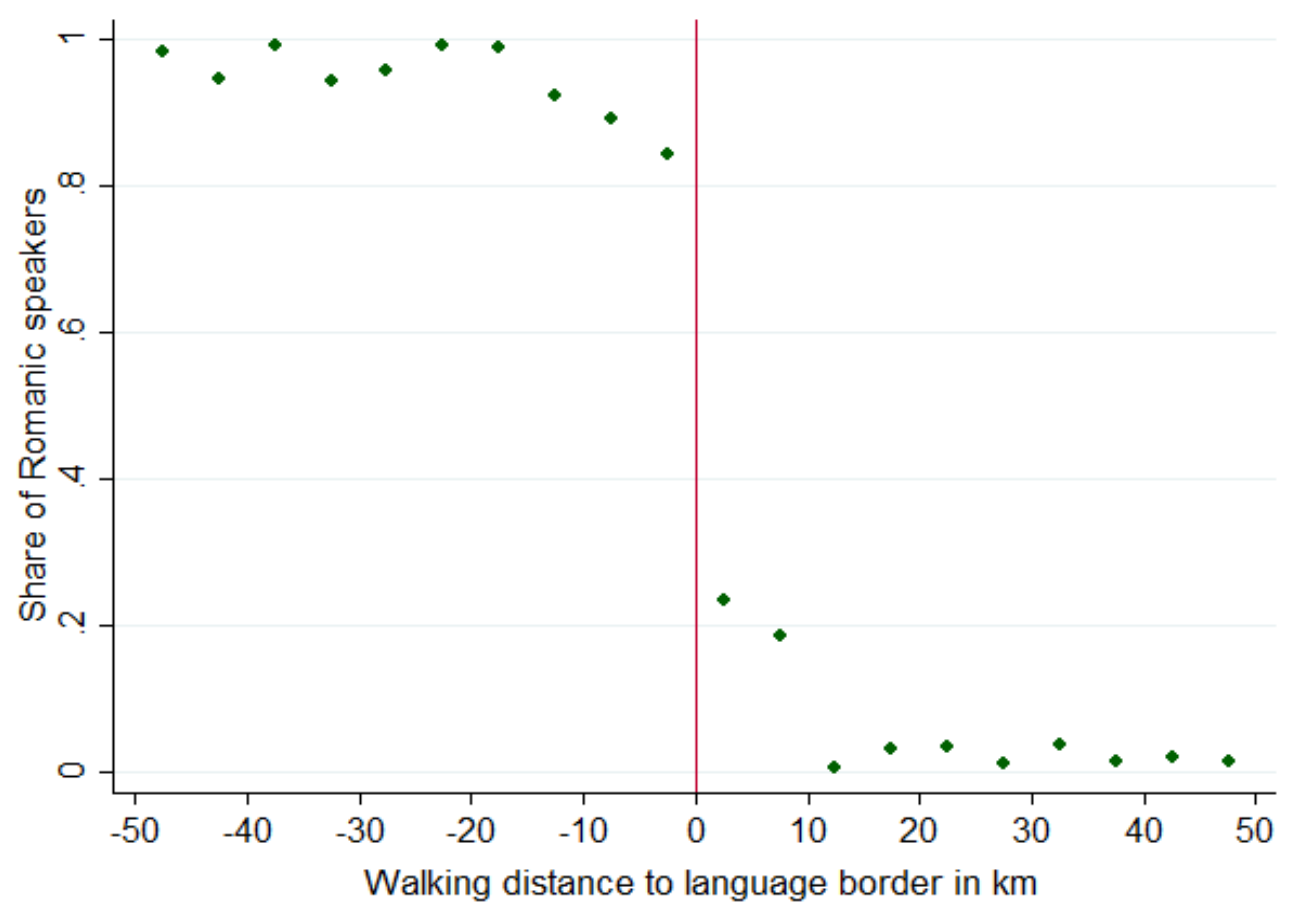


Figure 3. Household saving by language region and income levels

This figure shows the share of households that save at least CHF 100 per month by income levels and by language region in the four multilingual cantons (Bern, Fribourg, Graubünden, Valais) in 1999-2003. Low income (middle income, high income) households are households whose household income is in the lowest quartile (second \& third quartile, the highest quartile) of the income distribution in Switzerland per wave.

Source: Swiss Household Panel (1999-2003).

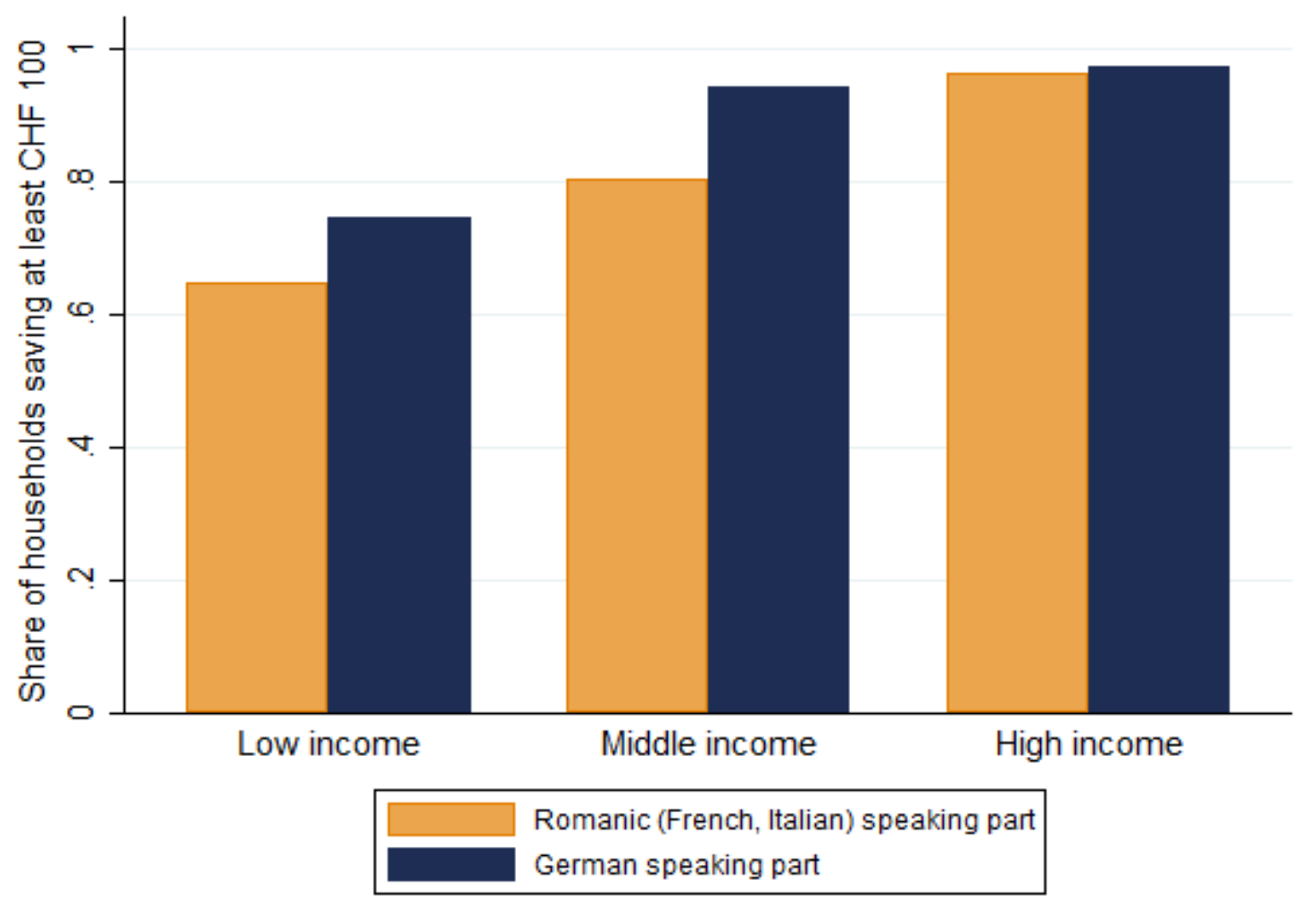


This table compares households' saving and expenses (Panel A) and household and household head characteristics (Panel B) of non-retired and employed low- and middle-income households located in the Romanic speaking part of Switzerland to households located in the German speaking part of Switzerland between 1999 and 2003. It only considers households located within $50 \mathrm{~km}$ from the language border. The last column tests the differences in means (t-test). The number of household observations $(\mathrm{N})$ are reported in parentheses. $* * *, * *, *$ denote statistical significance at the $0.01,0.05$ and 0.10 -level respectively. Definitions of the variables are provided in Appendix 1.

Panel A. Household financial decisions

\begin{tabular}{l|c|c|c}
\hline \hline & $\begin{array}{c}\text { Romanic } \\
\text { speaking part }\end{array}$ & $\begin{array}{c}\text { German } \\
\text { speaking part }\end{array}$ & Difference \\
\hline Saving & 0.768 & 0.891 & $-0.123^{* * *}$ \\
Saving (Pension Fund) & $(\mathrm{N}=267)$ & $(\mathrm{N}=376)$ & $(\mathrm{N}=643)$ \\
& 0.581 & 0.691 & $-0.111^{* * *}$ \\
& $(\mathrm{~N}=267)$ & $(\mathrm{N}=376)$ & $(\mathrm{N}=643)$ \\
\hline Overspending & 0.113 & 0.050 & $0.064^{* * *}$ \\
& $(\mathrm{~N}=256)$ & $(\mathrm{N}=362)$ & $(\mathrm{N}=618)$ \\
\hline \hline
\end{tabular}

Panel B. Household and household head characteristics

\begin{tabular}{l|c|c|c}
\hline \hline & $\begin{array}{c}\text { Romanic } \\
\text { speaking part }\end{array}$ & $\begin{array}{c}\text { German } \\
\text { speaking part }\end{array}$ & Difference \\
\hline Household characteristics & 10.424 & 10.489 & -0.065 \\
Household income (Ln) & $(\mathrm{N}=267)$ & $(\mathrm{N}=376)$ & $(\mathrm{N}=643)$ \\
Household size & 2.775 & 2.894 & -0.118 \\
& $(\mathrm{~N}=267)$ & $(\mathrm{N}=376)$ & $(\mathrm{N}=643)$ \\
\hline Household head characteristics & & & \\
Male & 0.404 & 0.455 & -0.050 \\
University & $(\mathrm{N}=267)$ & $(\mathrm{N}=376)$ & $(\mathrm{N}=643)$ \\
Age & 0.142 & 0.138 & 0.004 \\
Swiss & $(\mathrm{N}=267)$ & $(\mathrm{N}=376)$ & $(\mathrm{N}=643)$ \\
Employed & 39.404 & 41.423 & $-2.018^{* *}$ \\
Self employed & $(\mathrm{N}=267)$ & $(\mathrm{N}=376)$ & $(\mathrm{N}=643)$ \\
& 0.910 & 0.923 & -0.013 \\
Unemployed & $(\mathrm{N}=267)$ & $(\mathrm{N}=376)$ & $(\mathrm{N}=643)$ \\
& 0.790 & 0.774 & 0.016 \\
& $(\mathrm{~N}=267)$ & $(\mathrm{N}=376)$ & $(\mathrm{N}=643)$ \\
\hline \hline
\end{tabular}


Figure 4. Saving by language region

This figure shows the share of households that save at least CHF 100 per month depending on the distance to the language border. The vertical line indicates the language border as detailed in the text. Dots left to (right to) the vertical line indicate the share of households that save at least CHF 100 per $10 \mathrm{~km}$ buckets in the Romanic-speaking part (German-speaking part).

Source: Swiss Household Panel (1999-2012).

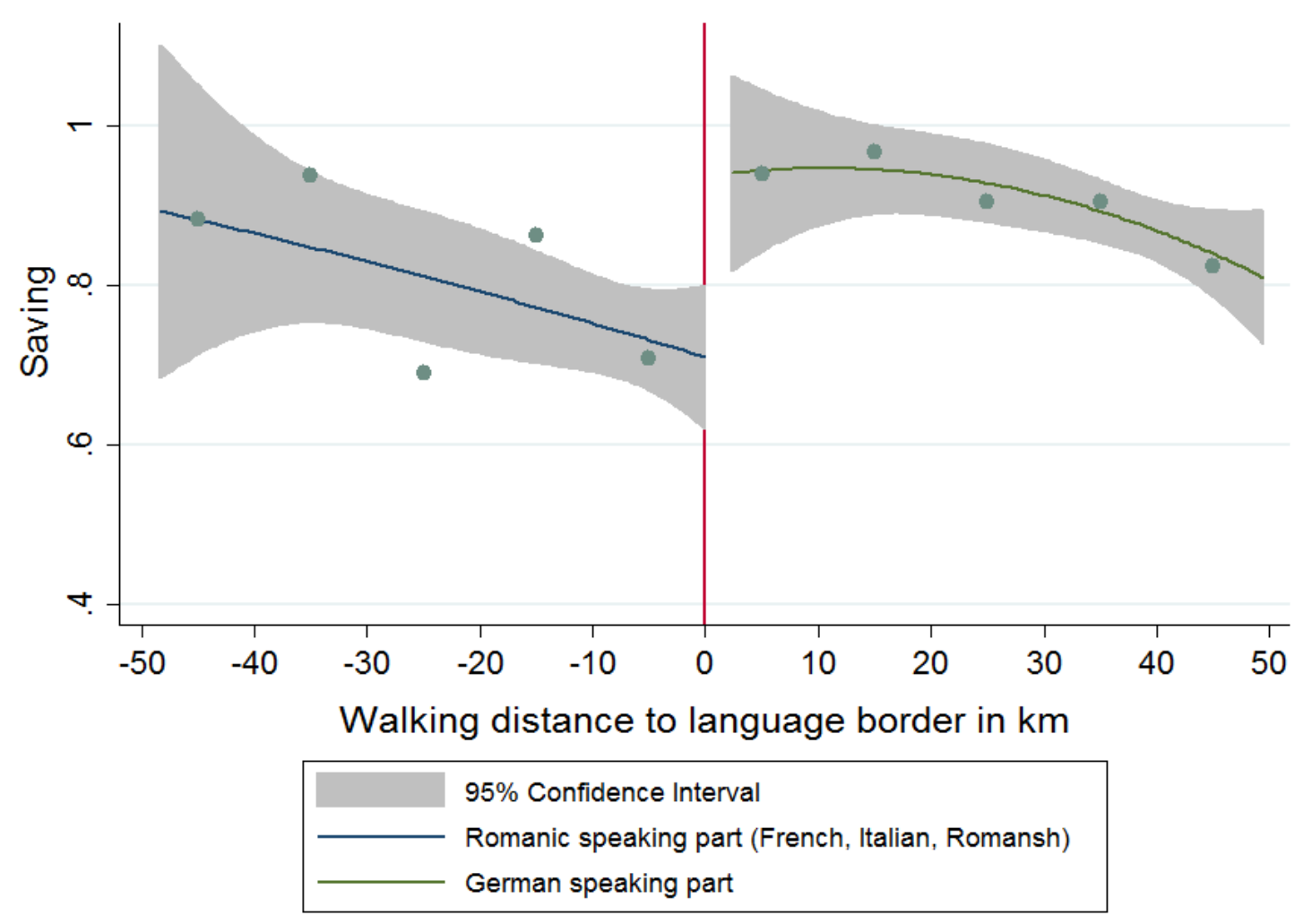


The dependent variable Saving is a binary variable indicating whether the household saves at least CHF 100 per month. Romanic speaking part is a binary variable indicating whether the household is located in the Romanic speaking part of Switzerland (German speaking part of Switzerland otherwise). Household control variables are Household income (natural logarithm), Household size, Male, University, Age, Swiss, Employed, Self employed, Unemployed. The regional control variable is the Unemployment rate on the district level. Definitions of the variables are provided in Appendix 1. Standard errors are clustered two-way on the household and municipality level and are reported in parentheses. ${ }^{* * *},{ }^{* *},{ }^{*}$ denote statistical significance at the $0.01,0.05$ and 0.10 -level, respectively.

Panel A. Saving (Bandwidth of 50km)

\begin{tabular}{|c|c|c|c|c|c|}
\hline $\begin{array}{r}\text { Survey Wave } \\
\text { Bandwidth } \\
\text { Dependent variable }\end{array}$ & $\begin{array}{c}1 \\
1999-2003 \\
50 \mathrm{~km} \\
\text { Saving }\end{array}$ & 2 & 3 & $\overline{4}$ & 5 \\
\hline Romanic speaking part & $\begin{array}{c}-0.123^{* * *} \\
{[0.030]}\end{array}$ & $\begin{array}{c}-0.261 * * * \\
{[0.057]}\end{array}$ & $\begin{array}{c}-0.295^{* * *} \\
{[0.064]}\end{array}$ & $\begin{array}{c}-0.256^{* * *} \\
{[0.081]}\end{array}$ & $\begin{array}{c}-0.310 * * * \\
{[0.093]}\end{array}$ \\
\hline $\begin{array}{l}\text { Distance } \\
\text { Household controls } \\
\text { Regional controls } \\
\text { Canton FE }\end{array}$ & $\begin{array}{l}\mathrm{NO} \\
\mathrm{NO} \\
\mathrm{NO} \\
\mathrm{NO}\end{array}$ & $\begin{array}{l}\text { Linear } \\
\text { YES } \\
\text { NO } \\
\text { YES }\end{array}$ & $\begin{array}{l}\text { Linear } \\
\text { YES } \\
\text { YES } \\
\text { YES }\end{array}$ & $\begin{array}{c}\text { Quadratic } \\
\text { YES } \\
\text { NO } \\
\text { YES }\end{array}$ & $\begin{array}{c}\text { Quadratic } \\
\text { YES } \\
\text { YES } \\
\text { YES }\end{array}$ \\
\hline $\begin{array}{l}\text { Observations } \\
\text { Households } \\
\text { Municipalities } \\
\text { Mean of dependent variable } \\
\text { R-squared } \\
\text { Method } \\
\end{array}$ & $\begin{array}{c}643 \\
643 \\
199 \\
0.84 \\
0.027 \\
\text { OLS }\end{array}$ & $\begin{array}{c}643 \\
643 \\
199 \\
0.84 \\
0.142 \\
\text { OLS }\end{array}$ & $\begin{array}{c}643 \\
643 \\
199 \\
0.84 \\
0.144 \\
\text { OLS }\end{array}$ & $\begin{array}{c}643 \\
643 \\
199 \\
0.84 \\
0.142 \\
\text { OLS }\end{array}$ & $\begin{array}{c}643 \\
643 \\
199 \\
0.84 \\
0.144 \\
\text { OLS }\end{array}$ \\
\hline
\end{tabular}


The dependent variable Tobacco smoked indicates whether the household head has ever smoked tobacco in her life. Romanic speaking part is a binary variable indicating whether the household is located in the Romanic speaking part of Switzerland (German speaking part of Switzerland otherwise). Household control variables are Household income (natural logarithm), Household size, Male, University, Age, Swiss, Employed, Self employed, Unemployed. The regional control variable is the Unemployment rate on the district level. Definitions of the variables are provided in Appendix 1. Standard errors are clustered two-way on the the municipality level and household level and reported in parentheses. ***, **, * denote statistical significance at the $0.01,0.05$ and 0.10 -level, respectively.

Panel A. Tobacco smoked (Bandwidth of 50km)

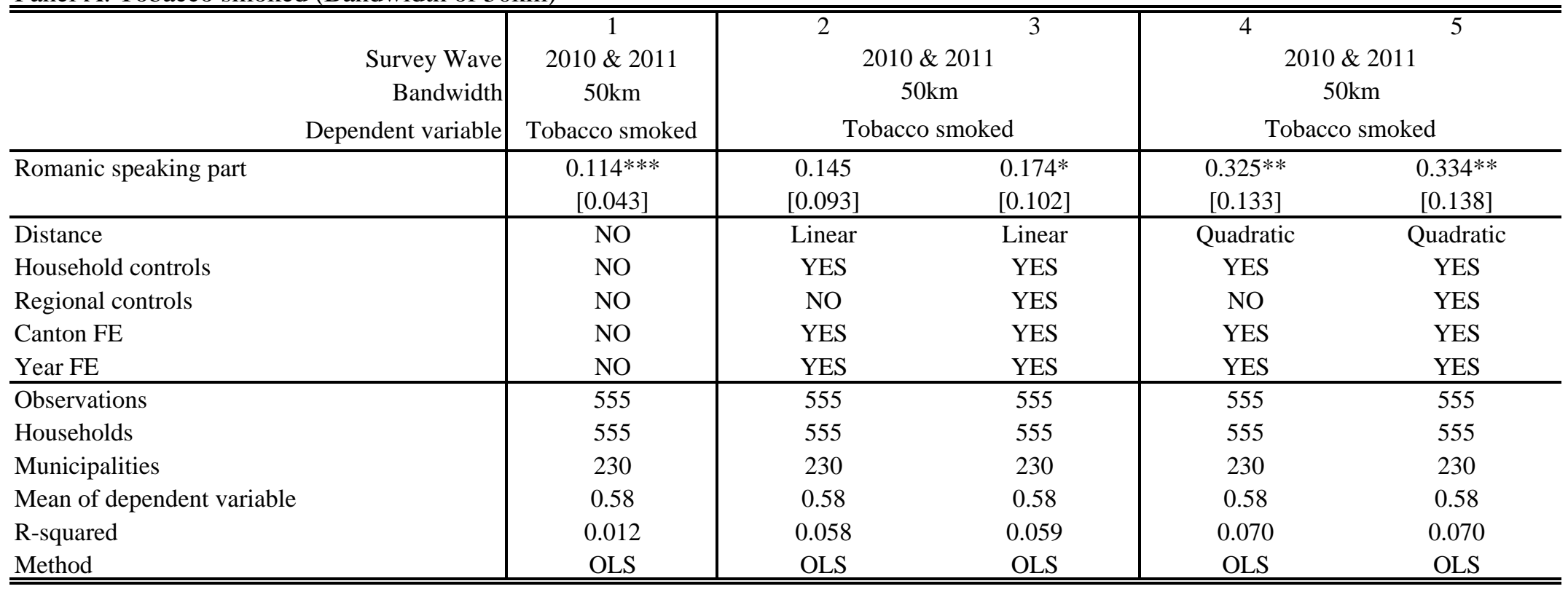


Table 4. Consumer credit in financial distress

The dependent variable Informal credit is a binary variable indicating whether the household borrows from family or friends in case of financial distress. The dependent variable Formal credit is a binary variable indicating whether the household borrows from banks in case of financial distress. Romanic speaking part is a binary variable indicating whether the household is located in the Romanic speaking part of Switzerland (German speaking part of Switzerland otherwise). Household control variables are Household income (natural logarithm), Household size, Male, University, Age, Swiss, Employed, Self employed, Unemployed. The regional control variable is the Unemployment rate on the district level. Definitions of the variables are provided in Appendix 1. Standard errors are clustered twoway on the the municipality level and household level and reported in parentheses. ***, **, * denote statistical significance at the 0.01 , 0.05 and 0.10 -level, respectively.

Panel A. Informal credit (Bandwidth of $50 \mathrm{~km}$ )

\begin{tabular}{|c|c|c|c|c|c|}
\hline \multirow[t]{2}{*}{$\begin{array}{r}\text { Survey Wave } \\
\text { Bandwidth } \\
\text { Dependent variable }\end{array}$} & \multirow{2}{*}{$\begin{array}{c}1 \\
1999-2012 \\
50 \mathrm{~km} \\
\text { Informal credit } \\
-0.008 \\
{[0.041]} \\
\end{array}$} & \multicolumn{2}{|c|}{$\begin{array}{ccc}2 & 3 \\
& & \\
& 1999-2012 \\
& 50 \mathrm{~km} \\
& \text { Informal credit } & \\
\end{array}$} & \multicolumn{2}{|c|}{$\begin{array}{ccc}4 & 5 \\
& & \\
& 1999-2012 \\
& 50 \mathrm{~km} & \\
& \text { Informal credit } & \\
\end{array}$} \\
\hline & & $\begin{array}{c}0.163^{* *} \\
{[0.070]}\end{array}$ & $\begin{array}{c}0.165^{* *} \\
{[0.073]}\end{array}$ & $\begin{array}{c}0.301^{* * *} \\
{[0.094]}\end{array}$ & $\begin{array}{c}0.303 * * * \\
{[0.097]}\end{array}$ \\
\hline Distance & NO & Linear & Linear & Quadratic & Quadratic \\
\hline Household controls & NO & YES & YES & YES & YES \\
\hline Regional controls & NO & NO & YES & NO & YES \\
\hline Canton FE & NO & YES & YES & YES & YES \\
\hline Year FE & NO & YES & YES & YES & YES \\
\hline Observations & 789 & 789 & 789 & 789 & 789 \\
\hline Households & 342 & 342 & 342 & 342 & 342 \\
\hline Municipalities & 180 & 180 & 180 & 180 & 180 \\
\hline Mean of dependent variable & 0.25 & 0.25 & 0.25 & 0.25 & 0.25 \\
\hline R-squared & 0.000 & 0.091 & 0.091 & 0.097 & 0.097 \\
\hline Method & OLS & OLS & OLS & OLS & OLS \\
\hline
\end{tabular}


Panel B. Formal credit (Bandwidth of 50km)

\begin{tabular}{|c|c|c|c|c|c|}
\hline $\begin{array}{r}\text { Survey Wave } \\
\text { Bandwidth } \\
\text { Dependent variable }\end{array}$ & $\begin{array}{c}1 \\
1999-2012 \\
50 \mathrm{~km} \\
\text { Formal credit } \\
\end{array}$ & \multicolumn{2}{|c|}{$\begin{array}{l}\text { 1999-2012 } \\
\text { 50km } \\
\text { Formal credit }\end{array}$} & \multicolumn{2}{|c|}{$\begin{array}{c}\text { 1999-2012 } \\
\text { 50km } \\
\text { Formal credit }\end{array}$} \\
\hline Romanic speaking part & $\begin{array}{c}0.027 \\
{[0.025]}\end{array}$ & $\begin{array}{c}0.057 \\
{[0.050]} \\
\end{array}$ & $\begin{array}{c}0.049 \\
{[0.051]}\end{array}$ & $\begin{array}{c}0.118 * \\
{[0.065]}\end{array}$ & $\begin{array}{c}0.110^{*} \\
{[0.066]}\end{array}$ \\
\hline $\begin{array}{l}\text { Distance } \\
\text { Household controls } \\
\text { Regional controls } \\
\text { Canton FE } \\
\text { Year FE }\end{array}$ & $\begin{array}{l}\text { NO } \\
\text { NO } \\
\text { NO } \\
\text { NO } \\
\text { NO }\end{array}$ & $\begin{array}{l}\text { Linear } \\
\text { YES } \\
\text { NO } \\
\text { YES } \\
\text { YES }\end{array}$ & $\begin{array}{l}\text { Linear } \\
\text { YES } \\
\text { YES } \\
\text { YES } \\
\text { YES }\end{array}$ & $\begin{array}{c}\text { Quadratic } \\
\text { YES } \\
\text { NO } \\
\text { YES } \\
\text { YES }\end{array}$ & $\begin{array}{c}\text { Quadratic } \\
\text { YES } \\
\text { YES } \\
\text { YES } \\
\text { YES }\end{array}$ \\
\hline $\begin{array}{l}\text { Observations } \\
\text { Households } \\
\text { Municipalities } \\
\text { Mean of dependent variable } \\
\text { R-squared } \\
\text { Method }\end{array}$ & $\begin{array}{c}789 \\
342 \\
180 \\
0.09 \\
0.002 \\
\text { OLS }\end{array}$ & $\begin{array}{c}789 \\
342 \\
180 \\
0.09 \\
0.075 \\
\text { OLS }\end{array}$ & $\begin{array}{c}789 \\
342 \\
180 \\
0.09 \\
0.075 \\
\text { OLS }\end{array}$ & $\begin{array}{c}789 \\
342 \\
180 \\
0.09 \\
0.077 \\
\text { OLS }\end{array}$ & $\begin{array}{c}789 \\
342 \\
180 \\
0.09 \\
0.078 \\
\text { OLS }\end{array}$ \\
\hline
\end{tabular}


Appendix 1. Variable definitions

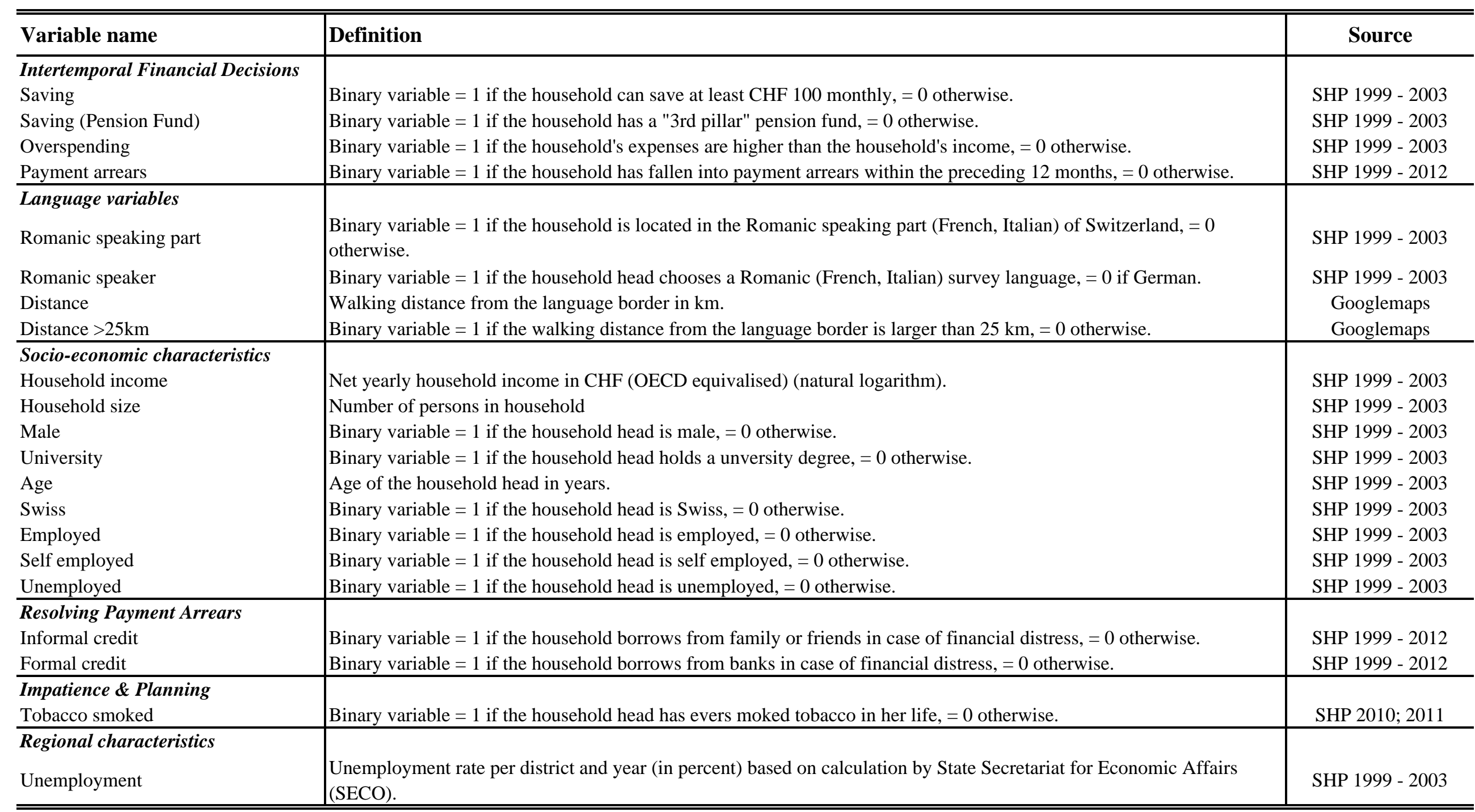


Appendix 2. Summary statistics

Definitions of the variables are provided in Appendix 1.

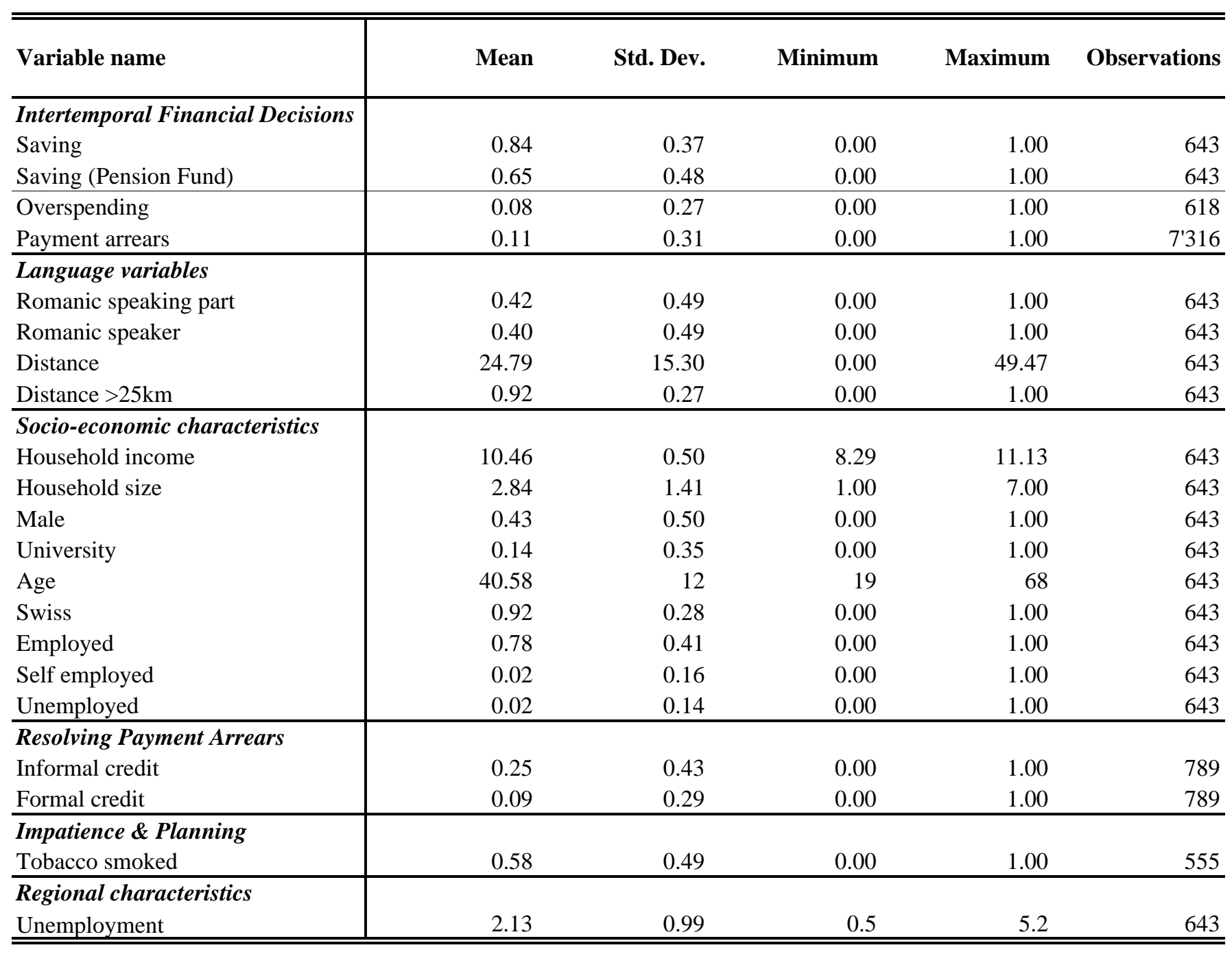




\section{Appendix 3. Household saving (Pension Fund) \& Overspending}

The dependent variable Saving (Pension Fund) indicates whether the household has a "3rd pillar" pension fund. Overspending indicates whether the the household's expenses are higher than the household's income. Romanic speaking part is a binary variable indicating whether the household is located in the Romanic speaking part of Switzerland (German speaking part of Switzerland otherwise). Household control variables are Household income (natural logarithm), Household size, Male, University, Age, Swiss, Employed, Self employed, Unemployed. The regional control variable is the Unemployment rate on the district level. Definitions of the variables are provided in Appendix 1. Standard errors are clustered two-way on the the municipality level and household level and reported in parentheses. ***, **, * denote statistical significance at the $0.01,0.05$ and 0.10 -level, respectively.

Panel A. Saving (Pension Fund) (Bandwidth 50km)

\begin{tabular}{|c|c|c|c|c|c|}
\hline $\begin{array}{r}\text { Survey Wave } \\
\text { Bandwidth } \\
\text { Dependent variable }\end{array}$ & $\begin{array}{c}1 \\
1999-2003 \\
50 \mathrm{~km} \\
\text { Saving (Pension } \\
\text { Fund) }\end{array}$ & $\begin{array}{l}2 \\
\text { Saving }\end{array}$ & $\begin{array}{l}3 \\
3 \\
\text { Fund) }\end{array}$ & $\begin{array}{l}4 \\
\text { Saving }\end{array}$ & $\begin{array}{l}5 \\
3 \\
\text { Fund) }\end{array}$ \\
\hline Romanic speaking part & $\begin{array}{c}-0.111^{* * *} \\
{[0.039]} \\
\end{array}$ & $\begin{array}{c}-0.261 * * * \\
{[0.078]}\end{array}$ & $\begin{array}{c}-0.268 * * * \\
{[0.087]} \\
\end{array}$ & $\begin{array}{c}-0.427 * * * \\
{[0.114]}\end{array}$ & $\begin{array}{c}-0.457 * * * \\
{[0.128]}\end{array}$ \\
\hline $\begin{array}{l}\text { Distance } \\
\text { Household controls } \\
\text { Regional controls } \\
\text { Canton FE }\end{array}$ & $\begin{array}{l}\text { NO } \\
\text { NO } \\
\text { NO } \\
\text { NO }\end{array}$ & $\begin{array}{l}\text { Linear } \\
\text { YES } \\
\text { NO } \\
\text { YES }\end{array}$ & $\begin{array}{l}\text { Linear } \\
\text { YES } \\
\text { YES } \\
\text { YES }\end{array}$ & $\begin{array}{l}\text { Quadratic } \\
\text { YES } \\
\text { NO } \\
\text { YES }\end{array}$ & $\begin{array}{c}\text { Quadratic } \\
\text { YES } \\
\text { YES } \\
\text { YES }\end{array}$ \\
\hline $\begin{array}{l}\text { Observations } \\
\text { Households } \\
\text { Municipalities } \\
\text { Mean of dependent variable } \\
\text { R-squared } \\
\text { Method } \\
\end{array}$ & $\begin{array}{c}643 \\
643 \\
199 \\
0.65 \\
0.013 \\
\text { OLS } \\
\end{array}$ & $\begin{array}{c}643 \\
643 \\
199 \\
0.65 \\
0.140 \\
\text { OLS } \\
\end{array}$ & $\begin{array}{c}643 \\
643 \\
199 \\
0.65 \\
0.140 \\
\text { OLS } \\
\end{array}$ & $\begin{array}{c}643 \\
643 \\
199 \\
0.65 \\
0.155 \\
\text { OLS } \\
\end{array}$ & $\begin{array}{c}643 \\
643 \\
199 \\
0.65 \\
0.155 \\
\text { OLS } \\
\end{array}$ \\
\hline
\end{tabular}


Panel B. Overspending (Bandwidth 50km)

\begin{tabular}{|c|c|c|c|c|c|}
\hline $\begin{array}{r}\text { Survey Wave } \\
\text { Bandwidth } \\
\text { Dependent variable } \\
\end{array}$ & $\begin{array}{c}1 \\
1999-2003 \\
50 \mathrm{~km} \\
\text { Overspending } \\
\end{array}$ & \multicolumn{2}{|c|}{$\begin{array}{c}\text { 1999-2003 } \\
\text { 50km } \\
\text { Overspending }\end{array}$} & \multicolumn{2}{|c|}{$\begin{array}{c}\text { 1999-2003 } \\
\text { 50km } \\
\text { Overspending }\end{array}$} \\
\hline Romanic speaking part & $\begin{array}{c}0.064^{* * *} \\
{[0.023]}\end{array}$ & $\begin{array}{c}0.096 * * \\
{[0.038]}\end{array}$ & $\begin{array}{c}0.130 * * \\
{[0.051]}\end{array}$ & $\begin{array}{c}0.144^{* * *} \\
{[0.045]}\end{array}$ & $\begin{array}{c}0.204 * * * \\
{[0.060]}\end{array}$ \\
\hline Distance & $\mathrm{NO}$ & Linear & Linear & Quadratic & Quadratic \\
\hline Household controls & NO & YES & YES & YES & YES \\
\hline Regional controls & NO & NO & YES & NO & YES \\
\hline Canton FE & NO & YES & YES & YES & YES \\
\hline Observations & 618 & 618 & 618 & 618 & 618 \\
\hline Households & 618 & 618 & 618 & 618 & 618 \\
\hline Municipalities & 197 & 197 & 197 & 197 & 197 \\
\hline Mean of dependent variable & 0.08 & 0.08 & 0.08 & 0.08 & 0.08 \\
\hline R-squared & 0.014 & 0.046 & 0.050 & 0.048 & 0.053 \\
\hline Method & OLS & OLS & OLS & OLS & OLS \\
\hline
\end{tabular}


The dependent variables are Household income, Household size, Male, University, Age, Swiss, Employed, Self employed, Unemployed. Romanic speaking part is a binary variable indicating whether the household is located in the Romanic speaking part of Switzerland (German speaking part of Switzerland otherwise). The regional control variable is the Unemployment rate on the district level. Definitions of the variables are provided in Appendix 1. Standard errors are clustered two-way on the the municipality level and household level and reported in parentheses. ***, **, * denote statistical significance at the 0.01, 0.05 and 0.10-level, respectively.

\begin{tabular}{|c|c|c|c|c|c|c|c|c|c|}
\hline $\begin{array}{r}\text { Survey Wave } \\
\text { Bandwidth }\end{array}$ & 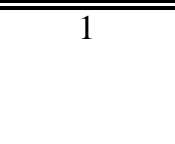 & $\overline{2}$ & 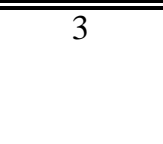 & 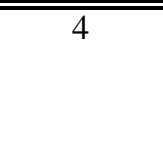 & $\begin{array}{c}5 \\
1999-2003 \\
50 \mathrm{~km}\end{array}$ & "6 & 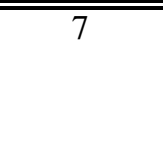 & 8 & $\overline{\overline{9}}$ \\
\hline Dependent variable & $\begin{array}{c}\text { Household } \\
\text { income }\end{array}$ & $\begin{array}{l}\text { Household } \\
\text { size }\end{array}$ & Male & University & Age & Swiss & Employed & Self employed & Unemployed \\
\hline Romanic speaking part & $\begin{array}{c}0.158 \\
{[0.131]} \\
\end{array}$ & $\begin{array}{c}-1.186^{* * *} \\
{[0.361]} \\
\end{array}$ & $\begin{array}{c}-0.219 \\
{[0.136]}\end{array}$ & $\begin{array}{c}0.054 \\
{[0.103]} \\
\end{array}$ & $\begin{array}{c}-0.705 \\
{[2.695]}\end{array}$ & $\begin{array}{c}0.049 \\
{[0.086]} \\
\end{array}$ & $\begin{array}{c}0.122 \\
{[0.123]}\end{array}$ & $\begin{array}{c}-0.079 \\
{[0.057]} \\
\end{array}$ & $\begin{array}{c}-0.091 \\
{[0.061]}\end{array}$ \\
\hline Distance & Quadratic & Quadratic & Quadratic & Quadratic & Quadratic & Quadratic & Quadratic & Quadratic & Quadratic \\
\hline Household controls & NO & NO & NO & NO & NO & NO & NO & NO & NO \\
\hline Regional controls & YES & YES & YES & YES & YES & YES & YES & YES & YES \\
\hline Canton FE & YES & YES & YES & YES & YES & YES & YES & YES & YES \\
\hline Observations & 643 & 643 & 643 & 643 & 643 & 643 & 643 & 643 & 643 \\
\hline Households & 643 & 643 & 643 & 643 & 643 & 643 & 643 & 643 & 643 \\
\hline Municipalities & 199 & 199 & 199 & 199 & 199 & 199 & 199 & 199 & 199 \\
\hline Mean of dependent variable & 10.46 & 2.84 & 0.43 & 0.14 & 40.58 & 0.92 & 0.78 & 0.02 & 0.02 \\
\hline R-squared & 0.025 & 0.038 & 0.007 & 0.022 & 0.020 & 0.011 & 0.004 & 0.015 & 0.013 \\
\hline Method & OLS & OLS & OLS & OLS & OLS & OLS & OLS & OLS & OLS \\
\hline
\end{tabular}


Appendix 5. Validity: Placebo test of language region

Saving is a binary variable indicating whether the household saves at least CHF 100 per month. Romanic speaking part is a binary variable indicating whether the household is located in the Romanic speaking part of Switzerland (German speaking part of Switzerland otherwise). Household control variables are Household income (natural logarithm), Household size, Male, University, Age, Swiss, Employed, Self employed, Unemployed. The regional control variable is the Unemployment rate on the district level. Definitions of the variables are provided in Appendix 1. Standard errors are clustered two-way on the the municipality level and household level and reported in parentheses. ${ }^{* * *},{ }^{* *}, *$ denote statistical significance at the 0.01, 0.05 and 0.10-level, respectively.

Panel A. Romanic speaking part

\begin{tabular}{|c|c|c|c|c|}
\hline $\begin{array}{r}\text { Survey Wave } \\
\text { Bandwidth } \\
\text { Dependent variable }\end{array}$ & \multicolumn{2}{|c|}{$\begin{array}{c}1999 \\
25 \mathrm{~km} \\
\text { Saving } \\
\end{array}$} & \multicolumn{2}{|c|}{$\begin{array}{c}1999 \\
25 \mathrm{~km} \\
\text { Saving }\end{array}$} \\
\hline Distance $>25 \mathrm{~km}$ & $\begin{array}{c}0.039 \\
{[0.112]} \\
\end{array}$ & $\begin{array}{c}0.004 \\
{[0.131]}\end{array}$ & $\begin{array}{c}0.048 \\
{[0.130]}\end{array}$ & $\begin{array}{c}-0.030 \\
{[0.145]}\end{array}$ \\
\hline $\begin{array}{l}\text { Distance } \\
\text { Household controls } \\
\text { Regional controls } \\
\text { Canton FE }\end{array}$ & $\begin{array}{l}\text { Linear } \\
\text { YES } \\
\text { NO } \\
\text { YES }\end{array}$ & $\begin{array}{l}\text { Linear } \\
\text { YES } \\
\text { YES } \\
\text { YES }\end{array}$ & $\begin{array}{l}\text { Quadratic } \\
\text { YES } \\
\text { NO } \\
\text { YES }\end{array}$ & $\begin{array}{l}\text { Quadratic } \\
\text { YES } \\
\text { YES } \\
\text { YES }\end{array}$ \\
\hline$\overline{\text { Observations }}$ & 267 & 241 & 267 & 241 \\
\hline Households & 267 & 241 & 267 & 241 \\
\hline Municipalities & 78 & 78 & 78 & 78 \\
\hline Mean of dependent variable & 0.77 & 0.77 & 0.77 & 0.77 \\
\hline R-squared & 0.165 & 0.162 & 0.165 & 0.163 \\
\hline Method & OLS & OLS & OLS & OLS \\
\hline
\end{tabular}




\begin{tabular}{|c|c|c|c|c|}
\hline $\begin{array}{r}\text { Survey Wave } \\
\text { Bandwidth } \\
\text { Dependent variable } \\
\end{array}$ & \multicolumn{2}{|c|}{$\begin{array}{c}1999 \\
25 \mathrm{~km} \\
\text { Saving }\end{array}$} & \multicolumn{2}{|c|}{$\begin{array}{c}1999 \\
25 \mathrm{~km} \\
\text { Saving }\end{array}$} \\
\hline Distance from the language border $>25 \mathrm{~km}$ & $\begin{array}{c}-0.014 \\
{[0.071]}\end{array}$ & $\begin{array}{c}0.039 \\
{[0.084]}\end{array}$ & $\begin{array}{c}0.017 \\
{[0.071]}\end{array}$ & $\begin{array}{c}0.054 \\
{[0.080]}\end{array}$ \\
\hline $\begin{array}{l}\text { Distance } \\
\text { Household controls } \\
\text { Regional controls } \\
\text { Canton FE }\end{array}$ & $\begin{array}{c}\text { Linear } \\
\text { YES } \\
\text { NO } \\
\text { YES }\end{array}$ & $\begin{array}{l}\text { Linear } \\
\text { YES } \\
\text { YES } \\
\text { YES }\end{array}$ & $\begin{array}{c}\text { Quadratic } \\
\text { YES } \\
\text { NO } \\
\text { YES }\end{array}$ & $\begin{array}{c}\text { Quadratic } \\
\text { YES } \\
\text { YES } \\
\text { YES }\end{array}$ \\
\hline$\overline{\text { Observations }}$ & 376 & 350 & 376 & 350 \\
\hline Households & 376 & 350 & 376 & 350 \\
\hline Municipalities & 109 & 109 & 109 & 109 \\
\hline R-squared & 0.131 & 0.124 & 0.132 & 0.124 \\
\hline Mean of dependent variable & 0.89 & 0.89 & 0.89 & 0.89 \\
\hline Method & OLS & OLS & OLS & OLS \\
\hline
\end{tabular}


The dependent variable Saving is a binary variable indicating whether the household saves at least CHF 100 per month. Romanic speaker is a binary variable indicating whether a Romanic (French, Italian) survey language (German otherwise). Household control variables are Household income (natural logarithm), Household size, Male, University, Age, Swiss, Employed, Self employed, Unemployed. The regional control variable is the Unemployment rate on the district level. Definitions of the variables are provided in Appendix 1. Standard errors are clustered on the municipality level and reported in parentheses. ***, **, * denote statistical significance at the 0.01 , 0.05 and 0.10-level, respectively.

\begin{tabular}{l|cc|cc}
\hline \hline & $\begin{array}{c}\text { Survey Wave } \\
\text { Dependent variable }\end{array}$ & \multicolumn{2}{c|}{$\begin{array}{c}\text { 1999-2003 } \\
\text { Saving }\end{array}$} & \multicolumn{2}{c}{$\begin{array}{c}1999-2003 \\
\text { Overspending }\end{array}$} \\
\hline Romanic speaker & $-0.110^{* * *}$ & $-0.114^{* * *}$ & $0.107 * * *$ & $0.117^{* * *}$ \\
& {$[0.036]$} & {$[0.040]$} & {$[0.026]$} & {$[0.030]$} \\
\hline Household controls & YES & YES & YES & YES \\
Religious controls & NO & YES & NO & YES \\
Regional controls & NO & YES & NO & YES \\
Canton FE & YES & YES & YES & YES \\
\hline Observations & 633 & 633 & 608 & 608 \\
Households & 633 & 633 & 608 & 608 \\
Municipalities & 195 & 195 & 195 & 195 \\
Mean of dependent variable & 0.08 & 0.08 & 0.08 & 0.08 \\
R-squared & 0.121 & 0.121 & 0.053 & 0.054 \\
Method & OLS & OLS & OLS & OLS \\
\hline \hline
\end{tabular}


Figure 5. Residuals by language region

This figure shows the residuals of the regression specified in Table 2 Column 2 in the four multilingual cantons (Bern, Fribourg, Graubünden, Valais) depending on the distance to the language border. The vertical line indicates the language border as detailed in the text.

Source: Swiss Household Panel (1999-2003).

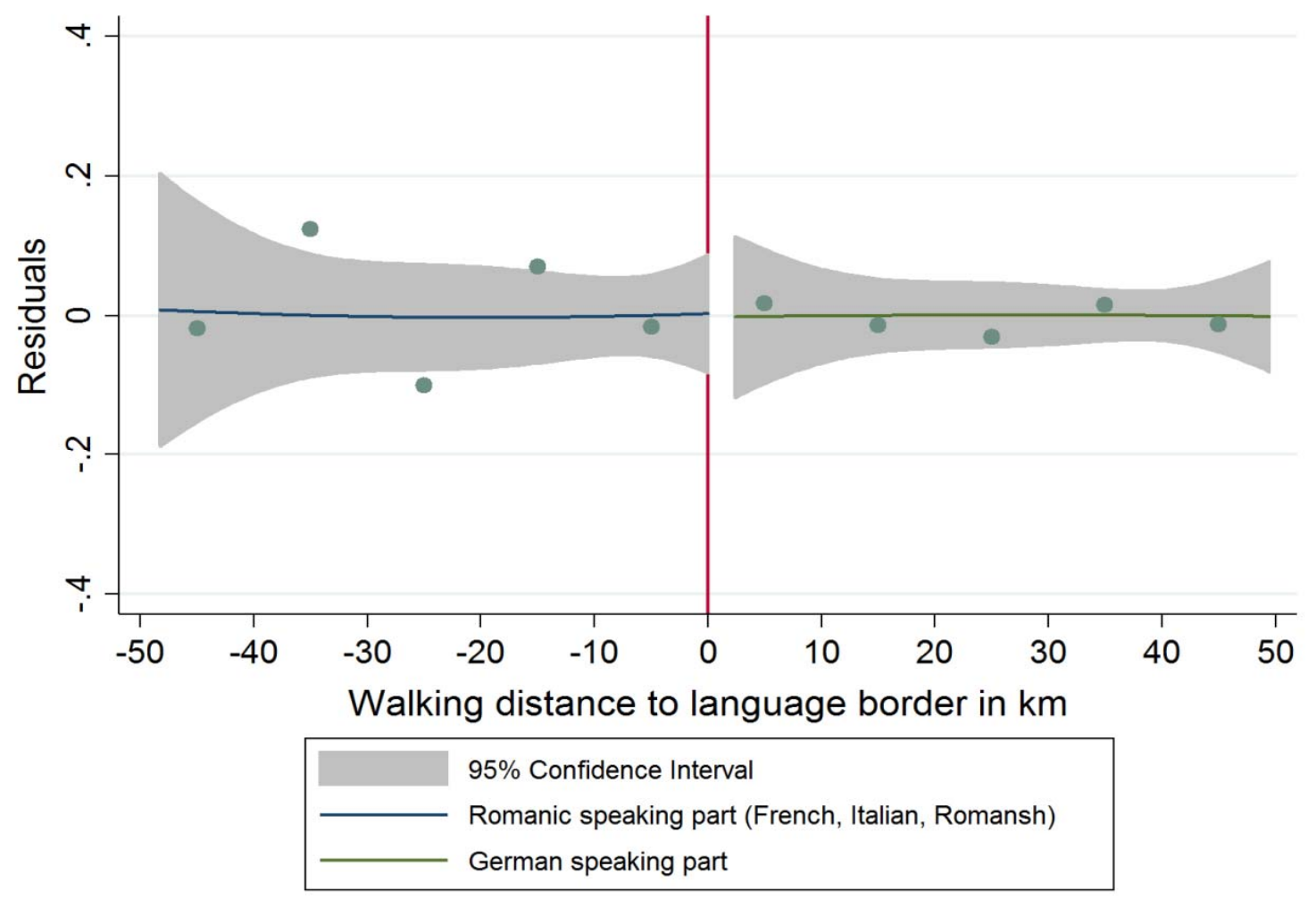

